\title{
LOS JEROGLÍFICOS DE LORENZO LOTTO PARA EL CORO DE SANTA MARIA MAGGIORE DE BÉRGAMO
}

\author{
THE HIEROGLYPHICS OF LORENZO LOTTO FOR THE CHOIR \\ OF SANTA MARIA MAGGIORE OF BERGAMO
}

\section{Andrea Schiavon}

Universidad de Granada

ABSTRACT: The drawings that Lorenzo Lotto made for the marquetry of the choir of Santa Maria Maggiore of Bergamo, executed between 1524 and 1532, highlight the special interest in hieroglyphs in Italian art. This article concentrates on the four examples of inlaid work that decorate the exterior facade of the choir, which were crafted based on the drawings of Lotto. The marquetry is analyzed by identifying its textual and visual sources, proposing as well an iconographical interpretation by considering the visual discourse that derives from the work as a whole.

\section{KEYWORDS: Lotto; Hieroglyphics; Choir; Marquetry; Bible.}

RESUMEN: Los dibujos de Lorenzo Lotto, ideados entre 1524 y 1532 para la creación de las taraceas del coro de Santa Maria Maggiore de Bérgamo, ponen de relieve el especial interés que tienen los jeroglíficos dentro del arte italiano. Este estudio se centra en las cuatro taraceas de la portada exterior del coro, realizadas a partir de los citados dibujos de Lotto. Son analizadas identificando sus fuentes textuales y visuales, proponiendo también una interpretación iconográfica que trata de aproximar el discurso visual que se desprende de todo el conjunto.

PALABRAS CLAVES: Lotto; jeroglíficos; coro; taraceas; Biblia. 


\section{INTRODUCCIÓN}

En el ámbito de mis estudios de doctorado dedicados a la llegada y el desarrollo de la moda jeroglífica en la península ibérica durante los siglos XVI y XVII, he podido apreciar el sentido diferente que los jeroglíficos alcanzaron en la España de la Edad Moderna, en comparación con los demás países europeos, sobre todo con la península italiana. Con el progreso de las investigaciones, esa tradición hispana está adquiriendo más relevancia para la mejor comprensión de las obras artísticas, y creo que puede ser interesante analizar una de las representaciones más tempranas de la aplicación jeroglífica dentro del arte italiano, dado el significativo papel que este territorio tuvo en la transmisión de esta manifestación emblemática a España.

La importancia de Italia para la renovación del interés y de los estudios sobre los jeroglíficos es indudable, y junto a las investigaciones sobre esta temática, ya desde mediados del siglo XV se empezaron a crear obras artísticas que incluyeron estos recursos tan atractivos como crípticos. ${ }^{1}$ En el ambiente veneciano -uno de los centros de vanguardia en este ámbito junto a Bolonia, Padua, Florencia y Roma- se formó Lorenzo Lotto (Venecia, 1480 - Loreto, 1556), artista entre los más eclécticos de la primera mitad del siglo XVI, capaz de conciliar su gran habilidad técnica con el gusto por los enigmas y los sentidos escondidos que impregnan sus obras. Pero, a pesar de su maestría y de la proliferación de los estudios sobre su obra en las últimas décadas, su nombre casi nunca aparece en los ensayos sobre la cultura jeroglífica del Renacimiento. Sin embargo, como revela su propia obra, este pintor puede ser adscrito entre los más genuinos y geniales creadores de jeroglíficos -o mejor dicho, de empresas jeroglíficas, concepto que forjé en mi investigación de grado (Schiavon, 2013: 67-76)- por sus creaciones para el coro de la iglesia de Santa María la Mayor en Bérgamo.

\section{LA INSTAURACIÓN DEL CORO}

Entre 1524 y 1532 Lotto prestó sus servicios al Consorcio de la Misericordia, institución que desde 1449 dirige la administración de la iglesia de Santa María la Mayor, capilla municipal de la ciudad bergamasca. Desde 1522 se decidió dotar al edificio religioso de un nuevo coro lignario, y el 12 de marzo de 1524, después de un primer encargo al pintor Nicolino Cabrini, el Consorcio se comprometió con el artista veneciano para la creación de cuadros de tema veterotestamentario que luego se utilizarían en calidad de patrones para la creación de las taraceas en los respaldos de la sillería del coro. El gran número de los episodios y su calidad artística hacen de este coro uno de los más sobresalientes de la península italiana, pero lo que convierte esta obra en unicum, más allá de las fronteras nacionales, se debe a un segundo contrato entre el Consorcio y Lorenzo Lotto. Se trata de la estipulación con fecha de 16 de junio de 1524, por la cual el veneciano todavía se comprometía a componer una serie de pinturas que servirían de modelo para las taraceas luego realizadas por el carpintero Giovan Francesco Capoferri. El hecho de la creación de esos modelos destaca en el propio contrato,

1. Sobre el redescubrimiento de la ciencia jeroglífica durante el Renacimiento, véase Alciato (2009: XLII-LXIV); Allen (1970); Castelli (1979); Dieckmann (1957); Giehlow (1915); Iversen (1993); Leal (2014); Savarese Gareffi (1980); Volkmann (1923); Wittkower (2006: 171-192). 
ya que una de las condiciones era que esos cuadros debían tener quella corespondenza in significato a li altri quadri sopra li quali se ponerano respectivamente ${ }^{2}$ [aquella correspondencia con el sentido de los otros cuadros sobre los cuales se pondrán respectivamente]. En la práctica, Lotto creó para cada una de las historias del Antiguo Testamento una cubierta simbólica que velaba (o revelaba) un sentido preciso por medio de unas relaciones significantes. Las ideaciones fueron el fruto solamente de la genialidad creativa del artista que, según sus palabras, las sacó una a una de su cervellazo ${ }^{3}$. De esa manera demostró su capacidad en la realización de originales empresas jeroglíficas que, por medio de unos pocos símbolos memorables, logran desvelar un mensaje mucho más amplio y rico, que se deriva de la palabra bíblica y su interpretación. ${ }^{4}$

En este artículo voy a concentrarme en las cuatro secciones de la portada exterior -dispuestas a modo de un iconostasio ortodoxo a un lado y otro del arco central-, las únicas del coro que estuvieron, y todavía permanacen, a la vista de los fieles, verdaderos destinatarios de estas composiciones jeroglíficas. De los cuatro episodios, de izquierda a derecha: El anegamiento del ejército del faraón, El arca de Noé, Judit y Holofernes, David y Goliat; los más importantes, bajo un punto de vista significante con base teológica, son los dos primeros mientras que los últimos contribuyen al sentido general del programa visual.

\section{EL ANEGAMIENTO DEL FARAÓN Y SU EJÉRCITO, IMAGEN DE SU ESTOLIDEZ}

Puesto como incipit del mensaje simbólico, la taracea del Anegamiento del faraón y su ejército fue entregada por Lotto muy probablemente el 4 de septiembre de $1527 .{ }^{5}$ A primera vista, la asociación con el episodio veterotestamentario homónimo no parece ser tan clara, y exactamente por eso el pintor veneciano, al enviar su dibujo a Capoferri, anotó el sentido correcto en su reverso. Desafortunadamente no ha quedado rastro alguno de los dibujos originales, negándonos de esta manera, además del trazo auténtico del artista, también la primigenia intención de la composición. Asimismo, tanto la falta de precedentes iconográficos como la rareza de la imagen ha dado pie a las más distintas interpretaciones, y de hecho, aunque relacionada de manera exacta con el anegamiento del ejército del faraón, la figura central de la cubierta fue interpretada tanto como el faraón cuanto como Moisés, otro protagonista de la historia del Éxodo. Llegados a este punto, es preciso señalar que según la identificación del personaje se deriva un cambio claro del mensaje. ${ }^{6}$ Hecha esta apreciación, el análisis

\footnotetext{
2. Véase «Patti, Lorenzo Lotto, 16 giugno 1524», en Cortesi Bosco (1987b: 119-120).

3. Carta 15 de enero de 1531, reproducida en Cortesi Bosco (1987b: 23-24).

4. He denominado empresas jeroglíficas a estas creaciones simbólicas de Lotto porque el artista parece conocer tanto la ciencia jeroglífica como el arte de forjar empresas, aunque ésta fue teorizada sólo a mediados del siglo XVI por Paolo Giovio. En este momento no ahondaré en el concepto de "empresas jeroglíficas", dado que el tema de este artículo es la comprensión del sentido de estas composiciones simbólicas del artista. Pueden verse con amplitud las razones que me llevaron a acuñar dicho concepto para el estudio en particular de estas obras de Lotto y analizo los elementos comunes entre jeroglíficos, emblemas y empresas, en Schiavon (2013: 41-76; 207-211). 5. Carta con fecha de 4 de septiembre de 1527 reproducida en Cortesi Bosco (1987b: 15-16).

6. Limitando el campo solamente a los estudios más analíticos sobre el coro y esta taracea, véase Van Den BergNoë (1974: 159 s.); Galis-Wronski (1977: 151-153); Cortesi Bosco (1987a: 468-469). Acerca de la taracea y el coro, aunque se trata de trabajos de menor importancia científica dada la escasez de fuentes y, sobre todo, las interpretaciones excesivamente divergentes entre sí, véase también Zanchi (1997); Zanchi (2006); Zanchi (2011).
} 
iconográfico debe empezar de la parte central de la composición, donde se puede ver a un hombre desnudo que viste solamente una capa y que va a lomos de un asno que avanza únicamente espoleado por las llamas que rasgan sus patas posteriores [fig. 1]. Lleva su cabeza ceñida por una jaula de pájaros, en la mano derecha un compás y en la izquierda un espejo convexo. Sobre esta figura hay una serpiente muerta con la cabeza casi desprendida que cuelga del resto del cuerpo, el cual, a su vez, yace enroscado entorno a una cinta que remata el conjunto significante. Completan la composición las dos figuraciones laterales que cuelgan de las prolongaciones de la cinta que descienden por ambos lados, donde se hallan, a la izquierda, un yelmo militar y una máscara y, a la derecha, un sombrero y la representación de unos ojos afectados de un evidente estrabismo.

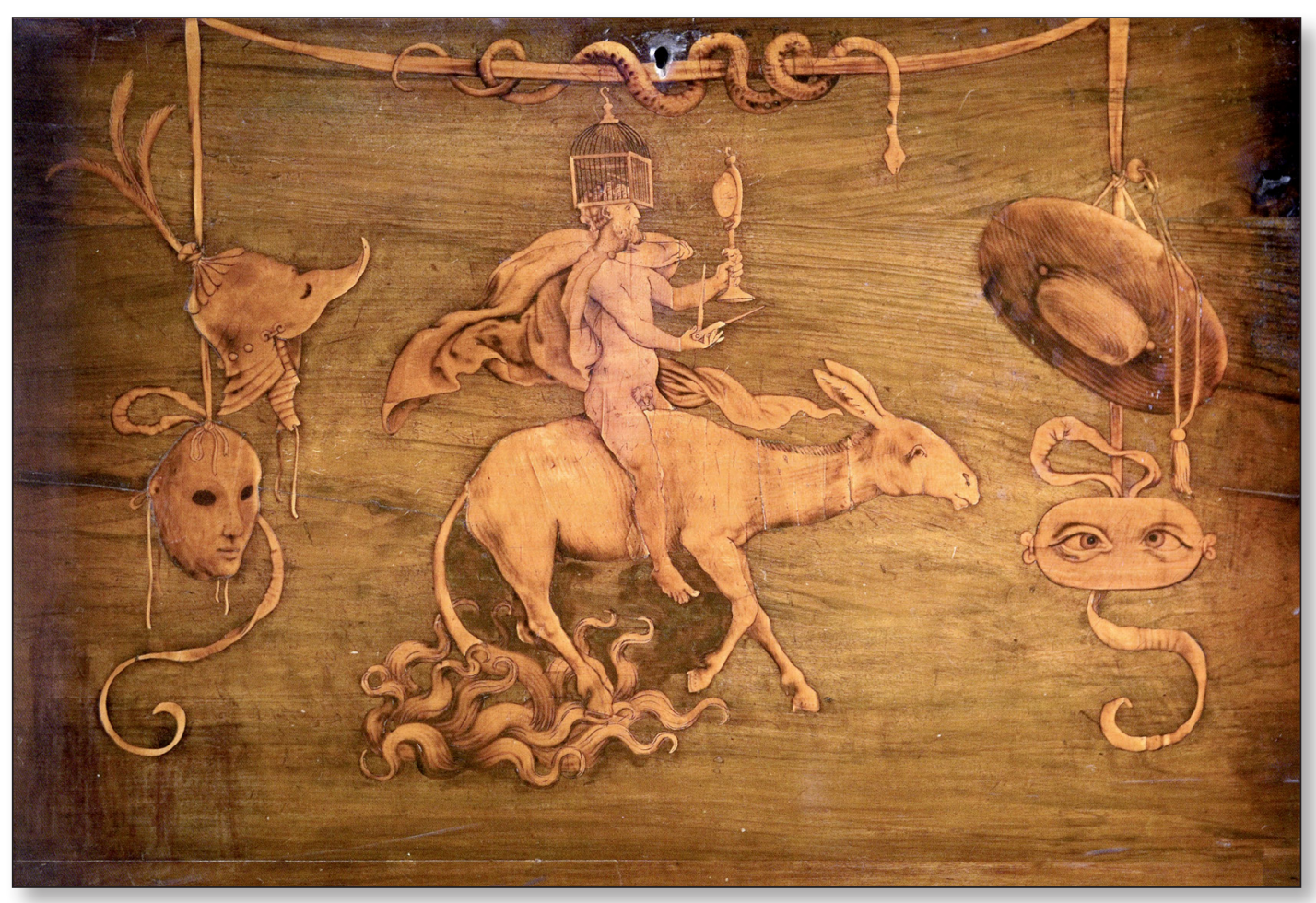

Fig. 1. Lorenzo Lotto (dibujo) y Giovan Francesco Capoferri (taracea). Estolidez de faraón. Cubierta simbólica (cm. 75,70x109,50). 1527-1530. Santa María la Mayor. Bérgamo.

Para despejar cualquier interpretación fantasiosa, hay que aclarar que el hombre desnudo representa sin duda al faraón, como confirma el mismo Lotto cuando denomina la historia y la relativa cubierta precisamente submersion de Pharaon. ${ }^{7}$ De esta manera delimita el episodio del paso del mar Rojo, poniendo énfasis en el infortunio del soberano, que junto a su ejército fue atropellado por las oleadas del mar. Aunque a primera vista no parece existir relación alguna con la historia de abajo, con una mirada más atenta, pode-

7. Véanse las misivas fechadas 18 de junio 1526, 18 de octubre 1526 y 3 de febrero 1527, donde siempre se lee «submersion de Pharaon" o "sumersion di Pharaone»; cfr. Cortesi Bosco (1987b: 265-269). 


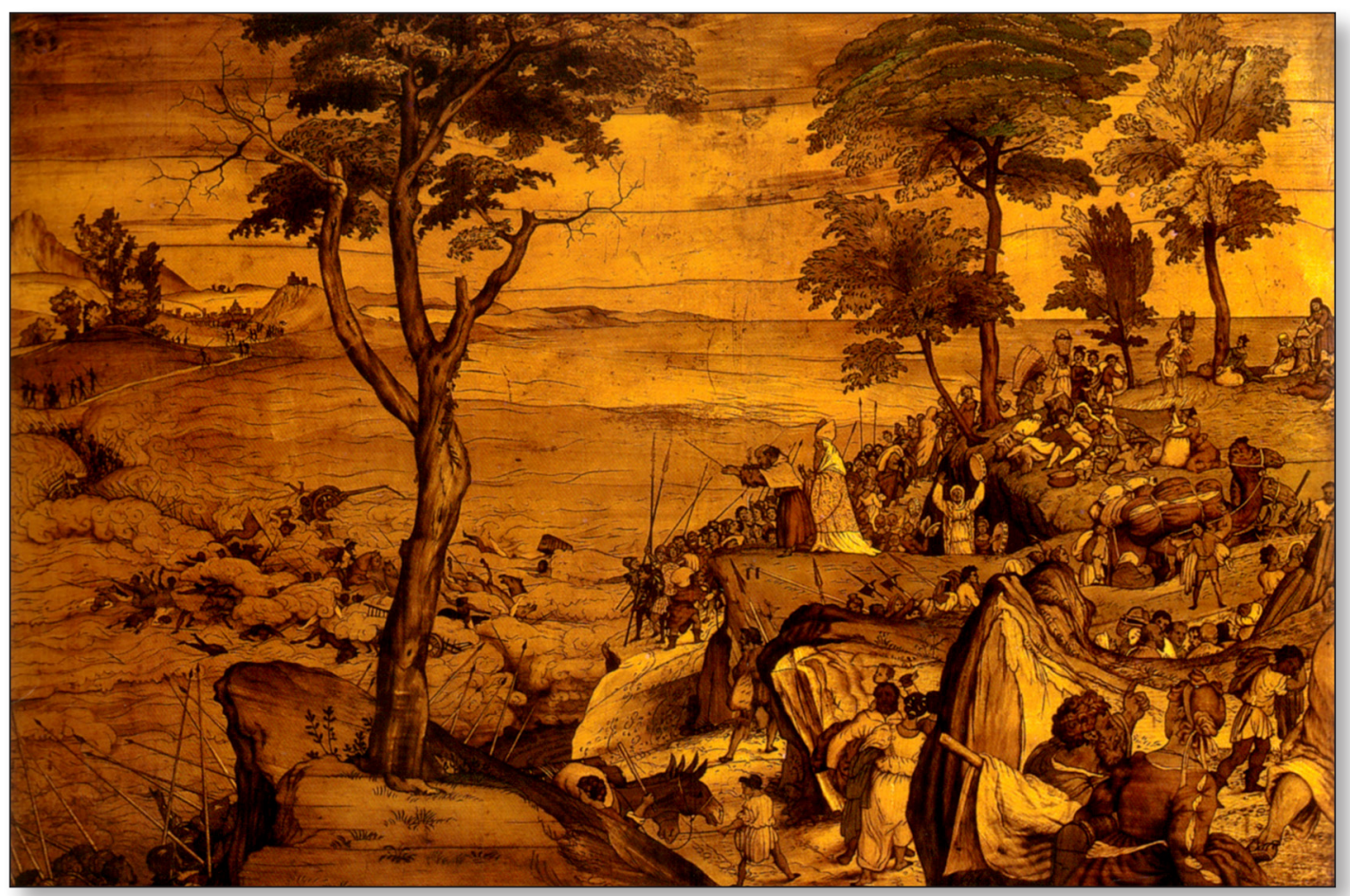

Fig. 2. Lorenzo Lotto (dibujo) y Giovan Francesco Capoferri (taracea). Ahogamiento de faraón. Historia bíblica. (cm. 68x99,80). 1527-1530. Santa María la Mayor. Bérgamo.

mos darnos cuenta de que a nivel visual, el artista lo pone en relación con la composición veterotestamentaria [fig. 2], donde se puede apreciar una división del campo visual entre el pueblo elegido llevado a salvo por Aarón y Moisés en el lado derecho, mientras que en el izquierdo vemos la figura del faraón que, con armadura, capa y diadema puestas, intenta erróneamente ponerse a salvo a lomo de su corcel entre las aguas encrespadas. Ahora bien, aunque fue recuperada la figura del faraón, estamos frente a una especie de transformación de los atributos del soberano hacia un sentido negativo. Así, el caballo se convierte en asno, el cuerpo se muestra desnudado de la preciosa armadura y el único signo recuperado de realeza está representado por la capa sobre sus hombros, mientras que la diadema se convierte en jaula. Se trata pues, de un intercambio de la figura del soberano por una alegoría que vuelca la clase social que habría tenido que manifestarse con sus acciones, ${ }^{8}$ y de este modo, se representa al rey de una manera ridícula y grotesca. La desnudez del faraón puede ser explicada si nos remitimos a los pasajes del Éxodo, donde aprendemos en dos ocasiones que el pueblo hebreo, al conquistar su libertad, desnudará al Egipto y a su gente; ${ }^{9}$ quizás exactamente con esta intención el faraón, representante del pueblo egipcio, aparece desnu-

8. Sb 6,24: "Abundancia de sabios salva el mundo, y un rey sensato da bienestar al pueblo".

9. «(...) et quando voi uscirete fori non ne partirete voti: ma la femina domandara ala sua vicina et ala sua albergatrice li vasi de argento et de auro et le vestimenta et metteretele sopra li vostri figlioli et le vostre figliore et spogliarete legypto» (Ex. 7), en Biblia vulgare, novamente impressa, corretta $\theta$ historiata (1525: f. XVIIv). Véase también Ex. 12, en ibid. (f. XXv). He consultado esta edición de la Biblia porque es coetánea a los dibujos de Lotto y porque es probable que el artista, quizás no muy docto en latín, utilizó una edición en vulgar, más conocida por la gente común a quien estaban destinadas sus creaciones.

IMAGO, NÚM. 9, 2017, I23-149 
do, como Dios había ordenado. Además, si volvemos a las Sagradas Escrituras aprendemos que la muerte del faraón y de su ejército fue causada por la obstinación del soberano. De hecho, en más de una ocasión, leemos que Dios endureció el corazón del faraón, ${ }^{10}$ o sea, lo volvió terco en sus erróneas convicciones, hasta persuadirlo de que no dejara salir al pueblo hebreo de su país y siguiera ciegamente en su fe pagana. En este sentido, nos ayuda el comentario del episodio realizado por Francesco Giorgio Veneto, que describe al faraón como un jefe muy obstinado, ${ }^{11}$ dilapidador y malversador. ${ }^{12}$

La obstinación infundida por Dios en el faraón llevó a éste último hacia la ruina tanto personal como de su pueblo, ${ }^{13}$ y esta ciega testarudez es la misma que transporta al soberano en sus elecciones. Lotto interpreta este sentido a través del faraón conducido en lomos de un asno, que es un animal tan terco que tiene que ser espoleado en su andar por llamas. De hecho, el asno puede referir una gran variedad de sentidos en el ámbito bíblico, donde muchas veces aparece según la acepción positiva de la humildad y la modestia (Ex 4,20; Jc 5,9-10; Nm 22-24; Za 9,9; Mt 21,1-7; Jn 12,14-15), en contraste con la realeza y la solemnidad que serían esperadas en el rey de las tierras de Egipto. Otra interpretación bíblica, en cambio, lo relaciona con la lujuria (Ez 23,20), ${ }^{14}$ la estupidez (Sal 32(31),9), y hasta con la pereza y estolidez, como se puede leer en la interpretación de un pasaje del Deuteronomio hecha por Euquerio. ${ }^{15}$ Además, es oportuno observar al respecto Das Narrenschiff, o Stultifera navis, de Sebastian Brant, ${ }^{16}$ obra que gozó de gran difusión por toda Europa entre el final del siglo XV y las primeras décadas del siglo XVI y cuyo tema principal es la estolidez humana. Al detener nuestra atención en la figura del asno, encontramos correspondencias interesantes con la imagen creada por Lotto cuando leemos: «El necio cabalga en el asno todo el año [...] El sabio es siempre mesurado; el impulsivo, con justicia cabalga en el asno» (Das Narrenschiff, 35, en Brant, 2011:174-175). En la obra alemana, además de otras noticias sobre este animal como sinónimo de ignorancia (Das Narreschiff, 66), aparecen también muchas ilustraciones protagonizadas por el cuadrúpedo [fig. 3]. Esto lleva a suponer que la obra franco-alemana puede ser una fuente textual y visual utilizada por Lotto, dada la temática afín y que Venecia, Treviso y Bérgamo, es decir las ciudades que vieron la presencia del artista en aquellas décadas, fueron áreas de intensos intercambios con el Norte de Europa.

Por lo que respecta al asno, siempre tenemos que prestar atención a las palabras de Ambrosio, que con su obra exegética parece ser el constante hilo conductor para captar las intenciones de Lotto en la creación de sus cubiertas simbólicas. El obispo milanés parece

10. "(...) ma io iduraro il suo cuore et multiplicaro li mei Segni» (Ex. 7), en ibid. (f. XVIIIr); "et come il signor haveva comandato indurasse il cuor de pharaone» (Ex. 7), en ibid. (f. XVIIIv); Exodo IX: "et il cuore di pharaone fue aggravato» (Ex. 9) en ibid. (f. XVIIIIr); "El Signor induro il cuor de Pharaone et non si volse lassar andare» (Ex. 10) en ibid. (f. XVIIIIv); véase también Ex. 13, en ibid. (f. XXv); Ex. 13, en ibid. (f. XXIr).

11. Francesco Giorgio Veneto, De harm. Mund., I,7, 16: "duce suo pertinacissimo».

12. Ibid.: "Pharaone, id est dissipatore et concussore cum suis Aegyptiis».

13. Pr 28,14: "Dichoso el que se mantiene alerta, el terco caerá en la desgracia».

14. Euquerio, form., I, 5; PL L, 752C, comenta así el pasaje bíblico: rursus asino designatur immoderata petulantium luxuria, ut propheta.

15. Form., I, 5; PL L, 752A-C. Sentido parecido se encuentra en el Bestiario de Thaün (ed. E. Mall), cfr. Morini, 1996 116-117. Véase también Dante, Conv., II, 7, 4, donde se recuperan las palabras de Boecio sobre el asno (cfr. Cons. Phil., IV, pr. 3; PL LXIII, 800A), y Conv., IV, 15, 6. Valeriano cita muchos ejemplos que testimonian la torpeza y la locura del animal, y refiere también que el asno, según Plutarco (Bruta anim., 992D), es completamente desprovisto de razón, de la misma manera que muchos hombres; cfr. Valeriano (1556: XII, f. 87v).

16. Brant (1494). Fue desde el 1497 gracias a la paráfrasis latina realizada por Jacob Locher bajo el título de Stultifera navis, impresa en Basilea, que la obra gozó de un alcance a nivel europeo. 


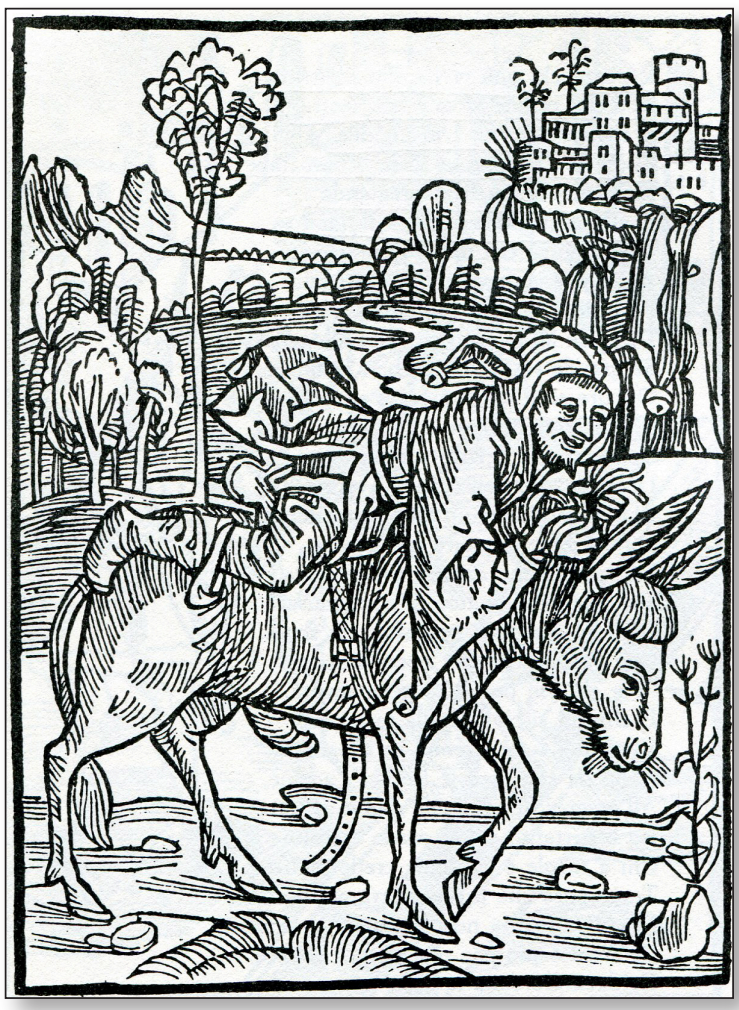

Fig. 3. Grabado extraído de Das Narrenschiff. Basilea. 1494 referirse perfectamente a esta composición, cuando explica que: "Piger asinus, et expositus ad predam, sensuque tardior quid aliud docet, nisi nos vivaciores esse debere, nec desidia corporis animique pigrescere, confugere ad fidem, qux onera gravia allevare consueverit?» (hex. 6, VI, 3, 11; PL XIV, 261B). Se trata de un propósito que vuelve a relacionarse también con el atributo de la jaula de pájaros, que en breve voy a analizar. Sin embargo, tengo que subrayar un hecho fundamental para la comprensión de esas ideaciones simbólicas, o sea que Lotto emplea una especie de doble registro lingüístico para otorgar sentido a sus composiciones, y, sobre todo, para que los fieles puedan entenderlas. El cuadrúpedo se eleva a terca cabalgadura, bien relacionada con el estólido, pero esa peculiaridad no fue divulgada solamente a nivel literario, sino que también indudablemente a nivel popular y fácilmente asociada al animal. Ser conducido a lomos de asno era castigo público, y por eso todos podían acercar esta figura a conceptos similares. Se

trata de una pena difundida por todo el territorio italiano, por la cual el condenado por ignominia era obligado a cabalgar un asno por las calles de la ciudad para convertirse en el hazmerreír de toda la población. ${ }^{17}$ Así, al observar la cubierta jeroglífica podemos darnos cuenta de que la figura del faraón aparece representada exactamente durante una especie de castigo y, según esta óptica, Lotto pudo tomar la inspiración tanto de noticias literarias como de manifestaciones populares. En mi opinión, su ideación nos pone frente a una especie de triunfo al revés, capaz de unir la tradición de los eventos creados para victorias militares, matrimonios, encuentros diplomáticos de los notables del tiempo, con los castigos infamantes antes mencionados, que, además de la realidad, aparecían también representados sobre las llamadas estampas populares, de las cuales hablaré con respecto al próximo atributo. Al principio del Renacimiento los triunfos se referían a los de la Antigüedad romana, como atestiguan los bajorrelieves, medallas y fuentes literarias ${ }^{18}$ que se realizaron por toda Europa. Era costumbre crear carros siguiendo el ejemplo de los triunfos clásicos, como recogen en relatos literarios autores como Petrarca y, figurativamente, por artistas del calibre de

17. Cfr. Mellikof (1973); Tristan (1980); Zemon Davis (1980); Santyves (1935). Noticias históricas nos llegan por Plutarco (Quæst. Grxc., 2), pero, sobre todo en Josefo (AJ, XVIII, 356), al referir que los Partos consideran este castigo infligido a su jefe, Mitrídates, como la desgracia más infamante.

18. Las noticias más importantes sobre los triunfos clásicos las hallamos en Tito Livio, Ab Urbe Cond., X, 46; XXX, 45; Apiano, Hist., II, 101 ss.; Plutarco, Vit. Rom., XVI, 4-5; Vit. Aem., XXXII-XXXV; Josefo, BJ, VII, 5, 3-7; Suetono, Iul., XXXVII, 2; cfr. Martindale (1980: 53 s.).

IMAGO, NÚM. 9, 2017, I23-149 
Mantegna, ${ }^{19}$ pero también se levantaban arcos de triunfo efímeros por parte de los artistas de la corte, capaces de adornarlos con atributos que, a menudo, representaban las virtudes. Al acompañar al personaje celebrado, el cortejo desfilaba por recorridos preestablecidos al interior de la ciudad, exhibiendo toda su pomposa riqueza y gloria. ${ }^{20}$ De la misma manera, Lotto podría haber volcado el sentido de estos desfiles al enseñar a un pueblo avezado a esos acontecimientos la visión de la derrota del faraón en lugar de su triunfo.

Por lo que concierne al atributo de la jaula puesta a la altura de las sienes del soberano, puede reemplazar la diadema que ciñe la cabeza del faraón en la historia inferior. El símbolo de poder y nobleza se transforma todavía en atributo ridículo. Se trata, entonces, de una representación satírica similar a las que el pueblo estaba acostumbrado observar durante el carnaval, o también sobre las estampas populares, ${ }^{21}$ cuya gran difusión lleva a pensar que podían servir de inspiración también para los artistas. A pesar de que no fui capaz encontrar una concreta y contemporánea tipología iconográfica asimilable a esta ideación, conseguí hallar afinidades interesantes al dirigir la atención a las citadas estampas populares. La titulada O quanti sciocchi ne la gabbia vanno [Cuantos estúpidos que se van a la jaula] presenta varios personajes que suben una escalera hacia una jaula, que en la misma estampa es denominada una gabbia di matti [una jaula de grillos]. ${ }^{22}$ Así que este atributo puede remitir a la locura, de acuerdo con otra clase de estampa muy difundida, la del mundo al revés. En esta tipología se propone un cambio de papeles entre las clases sociales tradicionalmente constituidas, con una inversión de los valores y de los roles generalmente aceptados por la comunidad. La finalidad de éstos era la desacralización de la sociedad de entonces, desprovista de toda lógica y presa de locura. ${ }^{23}$ Asimismo, para la jaula es plausible una lectura a nivel más culto, posiblemente en correspondencia con la exégesis ambrosiana. ${ }^{24}$ Ésta a su vez remite a la tradición platónica, según la cual el alma está provista de alas que le ayudarían a levantar el vuelo y volver al cielo después de liberarse de la cárcel del cuerpo. ${ }^{25} \mathrm{El}$ faraón pereció con sus pecados y en consecuencia su alma no fue capaz de desplegar las alas,

19. Para la tradición literaria y figurativa de los triunfos durante el Renacimiento italiano, véase Martindale (1980: 45 s.); Carandente (1963).

20. Sobre el tema de los triunfos véase también Weisbach (1919). Para una recopilación de testimonios que describen los triunfos renacentistas italianos en toda su riqueza iconográfica se remite a Mitchell (1979), en particular págs. 39-40; 81-82; 85; 91; 143; Burckhardt (2004: 352-359). Un buen número de descripciones y relaciones de entradas, triunfos y fiestas del Renacimiento se encuentran en la colección de descripciones y relaciones puesta en línea por la British Library: http://www.bl.uk/treasures/festivalbooks/homepage.html

21. Generalmente publicadas en pequeños opúsculos o en folletos sueltos distribuidos a toda la población, sus representaciones, aunque cómicas y desmitificadoras, nacían a menudo de reelaboraciones literarias y dirigían críticas hirientes hacia algunas categorías laborales y a las clases más a la vista. Sin embargo, a causa de estos ataques, las estampas quedaban habitualmente anónimas. Sobre las estampas populares remito a Sorrento (1942); Omodeo (1965); Wilhelm (1996); Harms (1999).

22. Conservada en la Colección Venturi del gabinete de las Estampas «A. Davoti» de la biblioteca Panizzi de Reggio Emilia, se trata de una obra anónima del siglo XVI. Dos estampas más fueron indicadas por Cortesi Bosco, o sea, la «Moralitè» de Luca Bertelli y la «Gabbia dei matti» de Giuseppe Maria Mitelli; cfr. Cortesi Bosco (1987a: 469).

23. Por ejemplo, es el asno que monta el campesino, o dentro de una jaula hay un hombre mientras el ave lo observa desde el exterior. Sobre el mundo al revés véase Cocchiara (1956); Cocchiara (1963); Tristan (1980); Damianaki (2007).

24. Véase Bon. mort., IX, 38; PL XIV, 585A, donde se paragona la muerte a "in cavea claudatur», es decir, enjaular a las bestias representadas por nuestras pasiones, de modo que el alma liberada del cuerpo consiga emprender el vuelo. Otras referencias aparecen en Ambrosio Virginit., XVII, 107; PL XVI, 293C; XVIII, 111; PL XVI, 294D-295A; in Luc. 10, IV, 65; PL XV, 1632A; Cain et Ab., II, 9, 36; CSEL XXXII, 1, 407, 12; Isaac, IV; CSEL XXXII, 1, 662, 22; Abr., II, 8, 53; CSEL XXXII, 1, 606, 15; in Ps. 118, XV, 34; CSEL LXII, 349, 2.

25. Platón, Phd., 62b; 82e; Phdr., 246b y ss.; Ti., 81d; Resp., V, 469d. Sobre la continuidad y la propagación de esta doctrina en el pensamiento occidental véase Courcelle (2001). 
así que se quedó encerrada, o enjaulada, en el cuerpo. ${ }^{26}$ Parece que Lotto conoció esta doctrina vista su ideación de la cubierta, hoy llamada Alegoría del vicio $y$ de la virtud (1505) [fig. 4]. Pintada por el artista para que sirviera de protección al retrato del obispo Bernardo de' Rossi, podemos ver un amorcillo que, gracias a la ayuda de alas que han aparecido por todo su cuerpo, consigue ascender hasta el cielo por la ladera más difícil de la montaña, que alude al camino virtuoso (Pr 15,24).

El espejo y el compás llevados por el faraón son atributos comunes de una de las cuatro virtudes cardinales, ${ }^{27}$ la prudencia, ${ }^{28}$ que incita al individuo a elegir entre el bien y el mal. ${ }^{29}$ Se trata de la más importante entre las virtudes, porque representa el principio racional de todo lo que afecta la vida de un hombre y constituye el fin último de su existencia. ${ }^{30}$ Conforme a la moral del tiempo la prudencia es una cualidad vinculada al imperio del soberano, de acuerdo con, por ejemplo, el tratado Liber de regimine rectoris, ${ }^{31}$ donde se aprende que la prudencia "a lo retor é necessaria $^{32} "$ [al regente es necesaria]. Otro escrito que proporciona informaciones sobre el

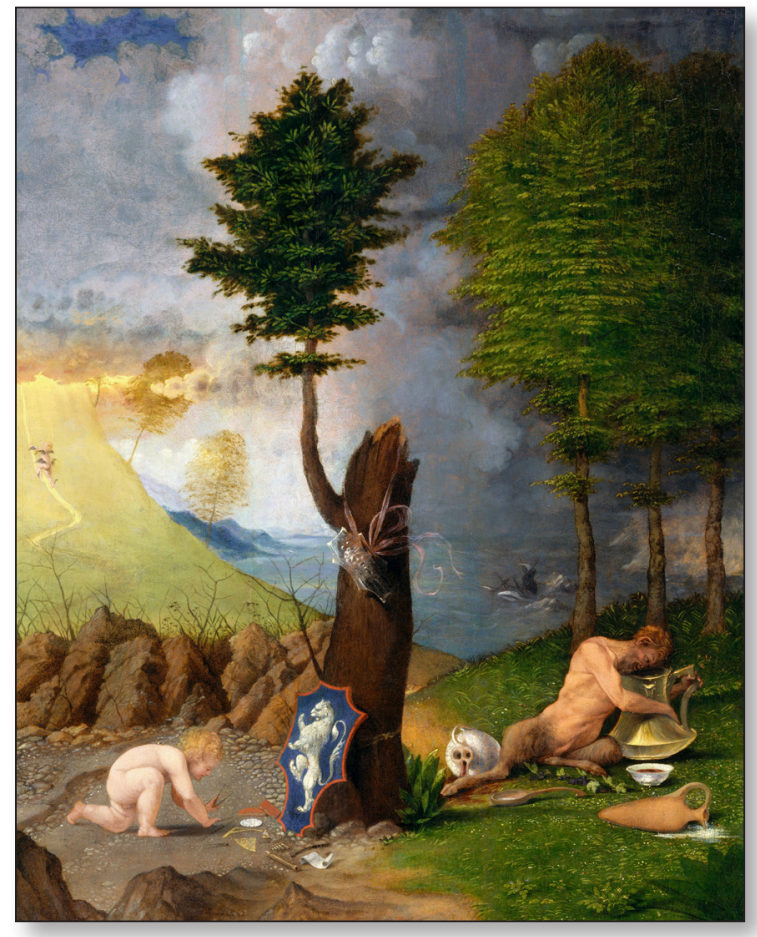

Fig. 4. Lorenzo Lotto. Alegoría del vicio y la virtud. Óleo sobre tabla (cm. 56,50x42,20). 1505. National Gallery of Art. Washington D.C.

26. Se trata de una idea que puede relacionarse también con la figura del asno según lo escrito por Valeriano, que otorga fundamento al pasaje bíblico que quiere significar por el animal la lujuria de las personas lascivas, con referencia a Sócrates que, en el Fedón, prescribió a los hombres concupiscentes y que conducen la vida con vituperio que, después de la muerte, serán transportados en asnos ( in asinos post obitum deijci»); cfr. Valeriano, 1556: XII, f. 88r; Platón, Phd., 81 e-82a; al respecto véase también Corpus Hermeticum, X, 24; 10, 8; Francesco Giorgio Veneto, De Harm. Mundi, I, 6, 13; III, 1, 7, que retoma de Sal 49(48), 13.

27. Ambrosio, in Luc. 10, V, 65-68; PL XV, 1654A-C, es el primero a denominar las cuatro virtudes como cardinales, recuperando una división procedente de Sócrates referida por Jenofonte, Mem., III, 9; cfr. Platón, Resp., IV, 440 ss. 28. Sobre el espejo y el compás como atributos de la representación de la prudencia y sus significados del conocimiento de sí mismo y de justa medida respectivamente, y además sobre el desarrollo de estos atributos con el pasar de los siglos, véase Schiavon (2013: 120-126). Además, acerca de la evolución de los atributos de la prudencia remito a Pfeiffenberger (1986); O’Reilly (1988); Katzenellenbogen (1989: 55).

29. Así en Cicerón, Fin., V, 67; Inv. rhet, II, 160; Off., I, 5; I, 153; Isidoro, Etym., II, 24, 5-6.

30. En este sentido véase Tomás de Aquino, Summa Theologix, Ia, IIae, q 61, art. 2; Ia, IIae, q 57, art. 4. Conforme a Marsilio Ficino, Theol. Plat., XIV, 6, la sociedad humana está regulada según el gobierno de una persona, la más anciana y prudente, que busca la perfecta armonía de su propia alma, mientras que los imprudentes nunca lo consiguen. También Erasmo de Rotterdam creía que no existía virtud sin la prudencia; cfr. Erasmi Roterodami, 1513: f. 140v, adagio CCLXXVI: "Iustitia in se virtutem complecitur omnem».

31. Obra de 1314 escrita en vulgar por el veneciano Paolino Minorita.

32. Cfr. Paolino Minorita, (1868: 5-7): "prudentia si é una vertude enluminativa dello intelecto humano a descerner entro quelle cose le qual sé o da seguire o da laxare» [la prudencia es una virtud que alumbra el intelecto humano en la elección entre las cosas que conseguir o dejar]. La traducción libre es mía.

IMAGO, NÚM. 9, 2017, I23-149 
tema es el Tractato nobilissimo della Prudentia et Iustitia, ${ }^{33}$ cuya primera parte está dedicada precisamente a esta imprescindible virtud en un gobernante. ${ }^{34}$ Relacionado a la virtud prudencial es otro atributo simbólico insertado por Lotto en su obra, es decir, la serpiente muerta que, junto a su cabeza casi toda desprendida del cuerpo, pende por encima del faraón. Del mismo modo que los dos atributos antes mencionados, también este animal puede ser atributo de la prudencia, pero, de acuerdo con el versículo neotestamentario donde se prescribe ser prudentes como las serpientes (Mt 10,16), ,5 no es mero atributo, sino incluso símbolo de la misma prudencia en su totalidad. En el caso de la taracea en cuestión, la representación del animal muerto precisa la incapacidad del faraón en tomar elecciones prudentes, virtud que en su imperio falleció. Sin embargo, aunque no he encontrado tipologías iconográficas semejantes, la peculiaridad de la representación con la cabeza parcialmente separada del cuerpo se logra despejar gracias al Fisiólogo, ${ }^{36}$ que nos explica cómo la serpiente, cuando es atacada por el hombre que quiere matarla, expone el cuerpo en su totalidad, protegiendo sólo la cabeza. De esa manera, cuando llegue el tiempo de la prueba, también el hombre tendrá que exponer a la muerte su cuerpo entero, guardando solamente la cabeza, es decir, "sin abandonar a Cristo». ${ }^{37}$ Esto último se verifica en las mismas Sagradas Escrituras que relatan que "la cabeza de todo hombre es Cristo". Además, todo este sentido del jeroglífico se refuta en el testimonio por cual el fallecimiento de una serpiente era asociado con un personaje notable como presagio del final de su poderío. ${ }^{38}$ Exactamente este sentido parece ser el de la representación de la cubierta, y por ello, la serpiente significaría no sólo la falta de prudencia del faraón, sino también el final de su dominio debido a no reconocer al pueblo elegido. ${ }^{39}$

Para concluir el análisis de esta composición hay que considerar las últimas dos secciones creadas por Lotto, o sea las zonas laterales, donde a espaldas y delante del faraón, casi a la manera de un cortejo triunfal, hay símbolos del poder militar y religioso que asisten al soberano en su gobierno. ${ }^{40}$ En este sentido, concurren para completar el mensaje originado de la palabra bíblica, según la cual el faraón se sirvió primero de sus sacerdotes paganos, o sea los sabios y los magos de Egipto, para que imitaran los milagros cumplidos por Aarón (Ex 7,10 s.), y luego del ejército para salir en persecución del pueblo elegido (Ex 14,6-9).

En resumen, Lotto nos quiere presentar el castigo del faraón causado por aquella estolidez que decidió perseguir en lugar de la prudencia. La estolidez en calidad de vicio contrario

33. Obra de Francesco de' Allegri, publicada en Venecia en 1508.

34. "Prudentia sia discretione perfecta in cognoscere il bene dal male, el bono dal pravo, el giusto dallo ingiusto et falso [...] $e$ questa prudentia [...] sopravanza a tute le altre virtude» [Que la prudencia sea perfecto discernimiento en distinguir el bien del mal, el bueno del pravo, el justo del injusto y falso [...] y esta prudencia [...] supera a todas las demás virtudes], en Alegris (1508: f. 5v). La traducción libre es mía.

35. Véase también Physiol., 11; Valeriano, 1556: XVI, f. $118 \mathrm{v}$.

36. Physiol., 11.; trad. esp. en Sebastián (1986: 89).

37. Ibid.; cfr. 1 Co. 11.3; 11.7; Francesco Giorgio Veneto, De Harm. Mund., II, 3.

38. Valeriano, 1556: XV, f. 112v-113r.

39. Entre los sentidos de la serpiente realizada por Lotto, además de la falta de prudencia y el fin de su dominio, hay también la muerte del faraón. De hecho, en Horapolo el rey se representa jeroglíficamente por una serpiente. Según esta noticia, Lotto pudo crear un nuevo jeroglífico para significar la muerte del rey, o sea, del faraón. El artista podía referirse a las noticias según las cuales la imagen de la serpiente servía de protección a la corona del faraón en la Antigüedad; cfr. Horapolo, Hieroglyphica, I, 59; I, 60; I, 63; entre las numerosas ediciones comentadas de Horapolo, me he valido de Hori Apollinis (1940: 122-127); Orapollo (2009: 149-151); para el vínculo entre la serpiente y la corona, y también para la traducción al castellano, cfr. Horapolo (201 1: 195-196).

40. Sobre el análisis de estos símbolos y la explícita crítica que Lotto quiso dirigir a la política y a la religión de su época, remito a Schiavon (2013: 142-163). 
a la virtud de la prudencia es temática que aparece en el ámbito artístico ya en las catedrales góticas del Norte de Europa, ${ }^{41}$ cuyo motivo fue recuperado en Italia por Giotto en la Capilla de los Scrovegni, aunque con iconografía diferente [fig. 5]. De hecho, el interior de este conjunto paduano presenta las personificaciones de las virtudes y de los vicios en las paredes opuestas, de modo que se puede apreciar la prudentia enfrentada a la stultitia. ${ }^{42} \mathrm{La}$ dualidad prudencia/estolidez es extensamente planteada en ámbito bíblico, ${ }^{43}$ de donde logramos extraer la explicación de esta personal invención jeroglífica lottesca, es decir, la imprudencia y el castigo del estólido. ${ }^{4}$

\section{EL ARCA DE NOÉ}

Justo después de la taracea del anegamiento del faraón se aprecia la traducción jeroglífica del episodio del arca de Noé. El dibujo alegórico fue entregado por Lorenzo Lotto el 18 de febrero de $1527^{45}$ y conseguimos asociarlo fácilmente a la historia veterotestamentaria, ya que presenta el momento en que la paloma, tras haber salido del arca, regresa con la ramita de olivo en el pico, de modo que Noé y los demás habitantes del arca entendieran que

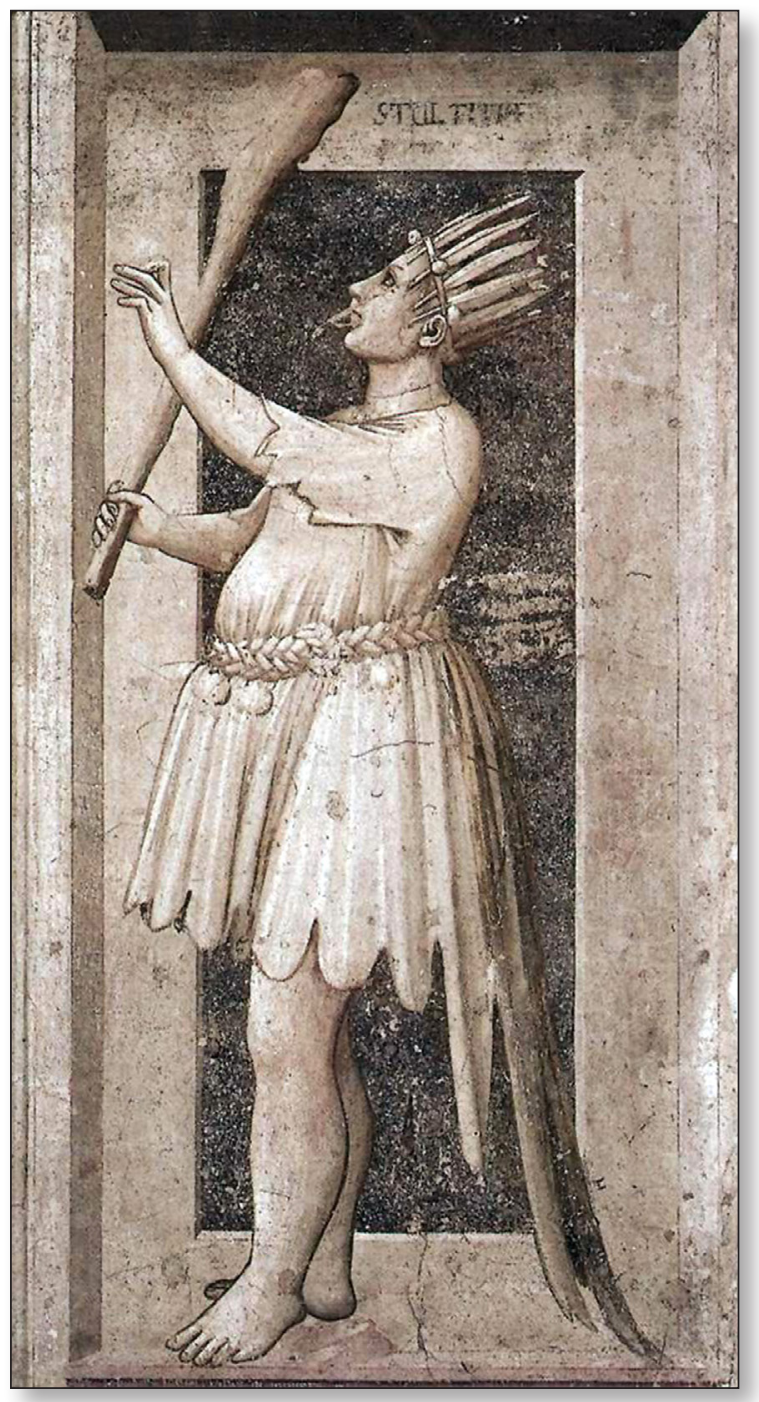

Fig. 5. Giotto di Bondone. Stultitia. Fresco (cm 120x55). 1306. Capillo de los Scrovegni. Padua.

41. Este emparejamiento se encuentra en los relieves de las catedrales de París, Amiens, Chartres, Laon, donde los bajorrelieves de la estolidez están puestos directamente de abajo de los de la prudencia, o, a lo más, los dos están puesto en directa correlación. En estos casos el vicio recupera la iconografía de la miniatura puesta a decorar la inicial historiada del salmo XIV, cuyo incipit reza: "Dixit insipiens»; cfr. Gifford (1974); Pfeiffenberger (1986: cap. IV-V).

42. Giotto representa la estolidez con una iconografía única dentro de su género y que probablemente toma inspiración desde modelos visuales del Norte de Europa, no solamente de las catedrales, sino también de tradiciones populares como, por ejemplo, la Fiesta de los locos, de las cuales el artista parece proponernos una especie de rey; cfr. Pisani (2004); Pfeiffenberger (1986: cap. IV-V).

43. Los comportamientos del sabio y del estólido son comparados en Si 21,11 s.; Pr. 10,23; 13,16; 14,8-9; 14,24. 44. Pr 3,35: "Los sabios heredan honores, los necios acumulan deshonra"; 9,12: "si eres sensato, lo serás en tu provecho; si te burlas, solo tú lo pagaras».

45. Carta de 18 de febrero de 1527 reproducida en Cortesi Bosco, 1987b: 11-12.

IMAGO, NÚM. 9, 2017, 123-149 
las aguas del diluvio se estaban retirando [fig. 6]. De hecho, la imagen nos enseña además las frondas de tres olivos que salen del mar aún agitado. Encontramos una clara proximidad entre esta figuración alegórica y el relato bíblico ilustrado abajo [fig. 7], donde, como en el episodio anterior, podemos distinguir una repartición entre el momento en que, a la derecha, Noé recibe las indicaciones de Dios y empieza a subir a bordo las parejas de animales, y a la izquierda, el inicio del diluvio con las oleadas engrosadas por la lluvia batiente que atropellan a todos. El arca logra flotar a pesar del asalto de los hombres desesperados que buscan un agarradero salvífico. Volviendo a la cubierta alegórica, encontramos el episodio del arca representado solamente en la mitad inferior de la tableta, que está rematada por la figura de un anaquel que tiene tres objetos no fácilmente identificables y que han atraído la atención de los estudiosos. Por encima de estos objetos destaca el mote «restauratio humana».

Las reglas creativas de las empresas y de los emblemas, composiciones muy en boga en aquella época, establecen que el mote y la parte figurativa de la cubierta se interpolen entre ellos, haciendo explícito el sentido del episodio que, gracias al lema, se hace patente en forma literaria. Para comprender lo mejor posible el profundo significado implícito en el relato bíblico, hay que prestar atención a los numerosos comentarios de este pasaje del Génesis, en especial, como de costumbre, al comentario de Ambrosio. ${ }^{46}$

Según un primer análisis que deriva de la lectura directa del pasaje bíblico, aprendemos que Dios notó cómo el mundo que había creado estaba corrupto, y por eso decidió destruir a toda la humanidad ${ }^{47}$. En este sentido, se prefigura lo que está escrito en el Evangelio, o sea, la salvación del ser humano por medio de la pasión del cuerpo divino y la purificación de la humanidad a través del sacramento del bautismo. ${ }^{48}$ A pesar de sus decisiones, Dios entabló amistad con el virtuoso Noé, y de esa manera, como escribe Ambrosio, "durante el diluvio los restos del género humano fueron salvados por medio del arca de Noé en su calidad de semillero para la restauración y la renovación futura ${ }^{49}{ }$. De acuerdo con estas palabras conseguimos comprender el mote utilizado por Lotto en esta tabla.

Por lo que respecta a los objetos colocados en el estante, nos parece claro que se pueden interpretar como herramientas empleadas, sobre todo, por orfebres y alquimistas. La primera explicación de esos elementos se refiere a la renovación de los metales sometidos a la obra alquímica, es decir, a su purificación y siguiente sublimación. Sin embargo, aunque hasta ahora los estudiosos se han encaminado solamente hacia esta exégesis, soy del parecer que la justa interpretación se puede encontrar, como de costumbre, entre las líneas de las Sagradas Escrituras, que nos proporcionan la clave para entender también las dos copelas que alternan los tres elementos de la repisa. Estos pequeños envases aparecen repletos y son interpretados con el sentido de «medida colmada» por parte del Señor. ${ }^{50}$ El último objeto en el estante es el más fácilmente reconocible. Se trata, en efecto, de una balanza con las medidas

46. Prueba de la importancia revestida por Ambrosio en el territorio bergamasco y de su conocimiento por parte de Lotto, hay que señalar la decoración a fresco realizada por el artista en el oratorio Suardi en Trescore, en 1524, donde los santos que impiden a los heréticos de cortar los sarmientos del Cristo-vid son Jerónimo y precisamente Ambrosio. 47. Genesi VI: «E vedendo Dio che molta malitia de l'huomini fusse in terra, e tutto el pensier del cor fusse intento al mal ogni tempo, fu pentito de haver fatto l'homo in terra [...] e toccato dal dolore del intrinseco core disse: "Distrugerò l'homo dala facia de la terra [...]". Et Nò̀ trovò gratia dinanci al Signor», en Biblia vulgare, novamente impressa, corretta $\theta$ historiata, 1525: f. IIv.

48. Ambrosio, Noe, V,11; PL XIV, 387A: "in Evangelio Dominus redempturus hominum genus passione sui corporis et emundaturus sanguine suo, sacramentoque baptismatis».

49. Ibid.: "quia in diluvio per arcam Noe servatae sunt reliquiae generis humani ad seminarium reparationis et renovationis futurae»; trad. esp. en Ambrosio de Milán, 2013: 271.

50. 1 Ts 2,16: «impiden que hablemos a los gentiles para que se salven, colmando en todo tiempo la medida de sus pecados". 


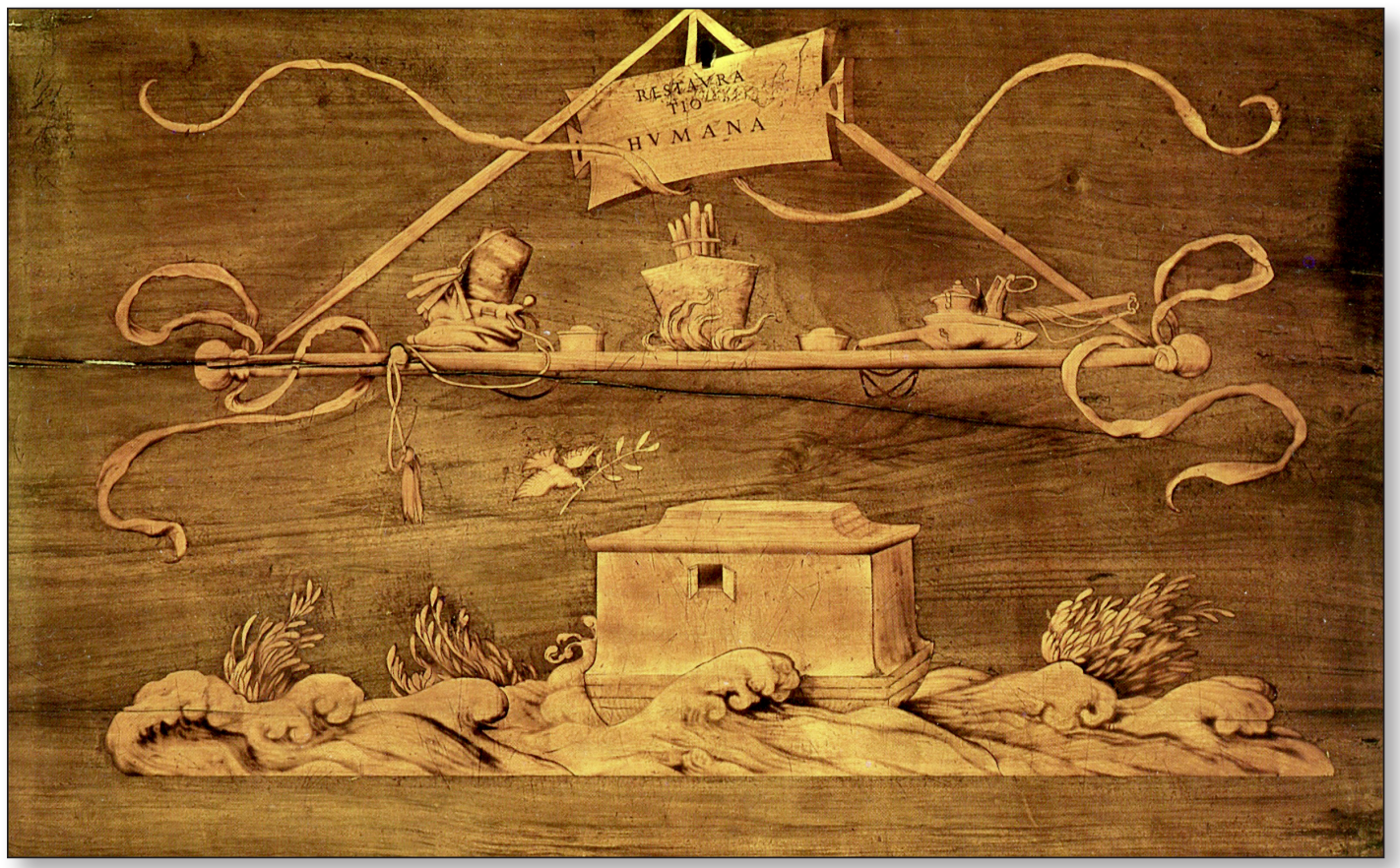

Fig. 6. Lorenzo Lotto (dibujo) y Giovan Francesco Capoferri (taracea). Restauratio humana. Cubierta simbólica (cm. 76,50x109,50). 1527. Santa María la Mayor. Bérgamo.

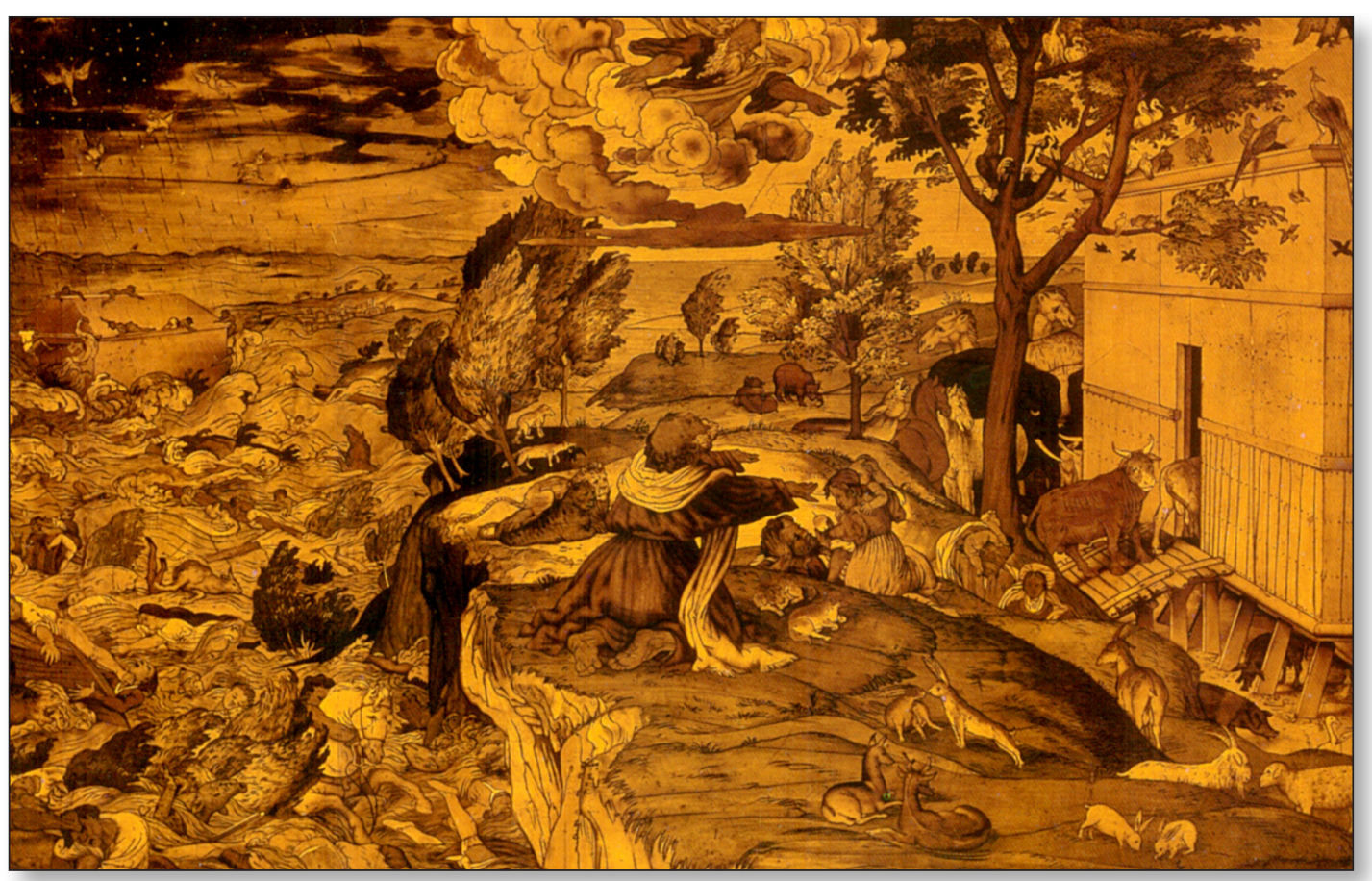

Fig. 7. Lorenzo Lotto (dibujo) y Giovan Francesco Capoferri (taracea). Arca de Noé. Historia bíblica (cm. 68x101). 1527. Santa María la Mayor. Bérgamo.

IMAGO, NÚM. 9, 2017, 123-149 
de peso puestas dentro de una bolsita y apoyadas encima del platillo. Ambrosio nos entera que el significado del nombre de Noé en lengua latina es «iustus vel requies», es decir, «justo» o "descanso", ${ }^{51}$ y análogamente, la balanza resulta ser el atributo más común de la justicia conforme a las palabras de la Biblia: "¿Acaso caminé con el embuste? ¿han corrido mis pies tras la mentira? Que me pese en balanza sin trampa y así comprobará mi honradez».52 Además de la balanza en calidad de medida de justicia, también las pesas resultan explicitadas en las Escrituras, donde aprendemos que "El Señor detesta la balanza engañosa, los pesos exactos lo complacen» (Pr 11,1), y sobre todo, "Balanza exacta es del Señor, obra suya las pesas de la bolsa» (Pr 16,11).

Para el primer objeto a la izquierda, comparto con Cortesi Bosco la identificación de éste con la piedra de toque ${ }^{53}$ que, en latín, es llamada coticŭla. ${ }^{54}$ Lotto la dibuja en su bolsita contenedora aflojada y con las muestras, cuyo contenido de oro es conocido, apoyadas en el pico. Para la confirmación de esta correspondencia concurren, además de la factura, aun los matices del objeto. Las muestras aludidas anteriormente, en efecto, son claras y fácilmente asociables al color del oro, mientras que la piedra de toque es oscura, negra, con rayas más claras marcadas por el toque de los objetos dorados que se intentan probar en su pureza. Esta coticŭla en lengua italiana es llamada "paragone», o "pietra di paragone», textualmente "comparación" o "piedra de comparación» en castellano, y esa referencia lexical es esencial para comprender el mensaje que se perpetúa a través de este objeto. ${ }^{55}$ De la misma manera en que se comprueba la autenticidad del oro por medio de esa piedra, por extensión su representación se puede entender como término de comparación, medida de juicio, criterio de evaluación, es decir, una prueba moral a la cual todo el género humano tuvo que someterse con el diluvio. Dios sometió a Noé a una prueba y, al resultar justo, fue elegido para volver a conferir vigor a la descendencia humana. En este sentido, parece ser atinente al adagio erasmiano "aurum lapide, auro mens hominum exploratur» [el oro se comprueba con la piedra, el alma humana con el oro], donde se refiere sobre un pasaje de Diógenes Laercio (I, 3, 71) ${ }^{56}$ al respecto de un mote de Quilón, que habría sentenciado que «por la piedra de toque se examina el oro, dando prueba de sus quilates, y por el oro se prueba al ánimo del hombre bueno o el del malo" (Diógenes Laercio, 1887: 58). Esta identificación, aunque correcta, hoy en día parece ser ardua por parte del público de entonces, pero el tema de la piedra de toque y de los ensayadores de hombres era conocido también a nivel popular, así que gracias a la colección de triunfos y canti carnascialeschi, ${ }^{57}$ realizada por Anton Francesco Grazzini, aprendemos cómo en territorio florentino se entonaba justo el Canto di saggiatori d'uomini ${ }^{58}$ [Canto de ensayadores de hombres].

51. Ambrosio, Noe, I, 2; PL XIV, 382A; trad. esp. en Ambrosio de Milán, 2013: 262.

52. Jb 31,5-6. Véase también Si 21,25 y, sobre todo, Lv 19,35-36: «No cometáis injusticias ni en los juicios, ni en medidas de longitud, de peso o de capacidad. Tened balanzas exactas, pesas exactas, medida exacta y fanegas exactas y cántaros exactos. Yo soy el Señor, vuestro Dios, que os sacó de Egipto».

53. La estudiosa llegó a esta identificación en 1987, con anterioridad la había interpretado con un lingote de oro; cfr. Cortesi Bosco, 1980: 130; Cortesi Bosco, 1987a: 396.

54. Cfr. Plinio, HN, XXXIIII, 126; Forcellini, E., Lexicon Totius Latinitatis, I, 882, s.v. «coticŭla».

55. Bajo la entrada "paragone» el Vocabolario degli Accademici della Crusca. Venecia, Giovanni Alberti, 1612, explica ser "pietra su la quale, fregando l'oro, e l'ariento, se ne fa paragone» [piedra sobre la cual, frotando el oro y la plata, se hace comparación]. Análogamente Vasari, en su discurso sobre la arquitectura en introducción a sus Vidas, nos entera que "se extrae también en Egipto y en algunos lugares de Grecia una piedra negra llamada piedra de toque ['paragone' en la versión original italiana], que se llama así porque, queriendo los orfebres comprobar la calidad del oro, se frota contra ella y se reconoce en su color, comparándose, la calidad del oro, y por esto se le llama piedra de toque [paragone]", en Vasari, 2004: 46.

56. Cfr. Erasmo da Rotterdam, 2013: 40-43, 421.

57. Es decir, una poesía con música que se cantaba en Florencia durante el carnaval.

58. Aquí algunas partes del canto, en Grazzini, 1750: 421-422: "Noi fummo già maestri partitori/Dell'oro, e dell'argento;/Ma adesso andiam facendo sperimento/Degli uomin, come d'uomin saggiatori,/[...]Come col paragone/L'oro falso dal 

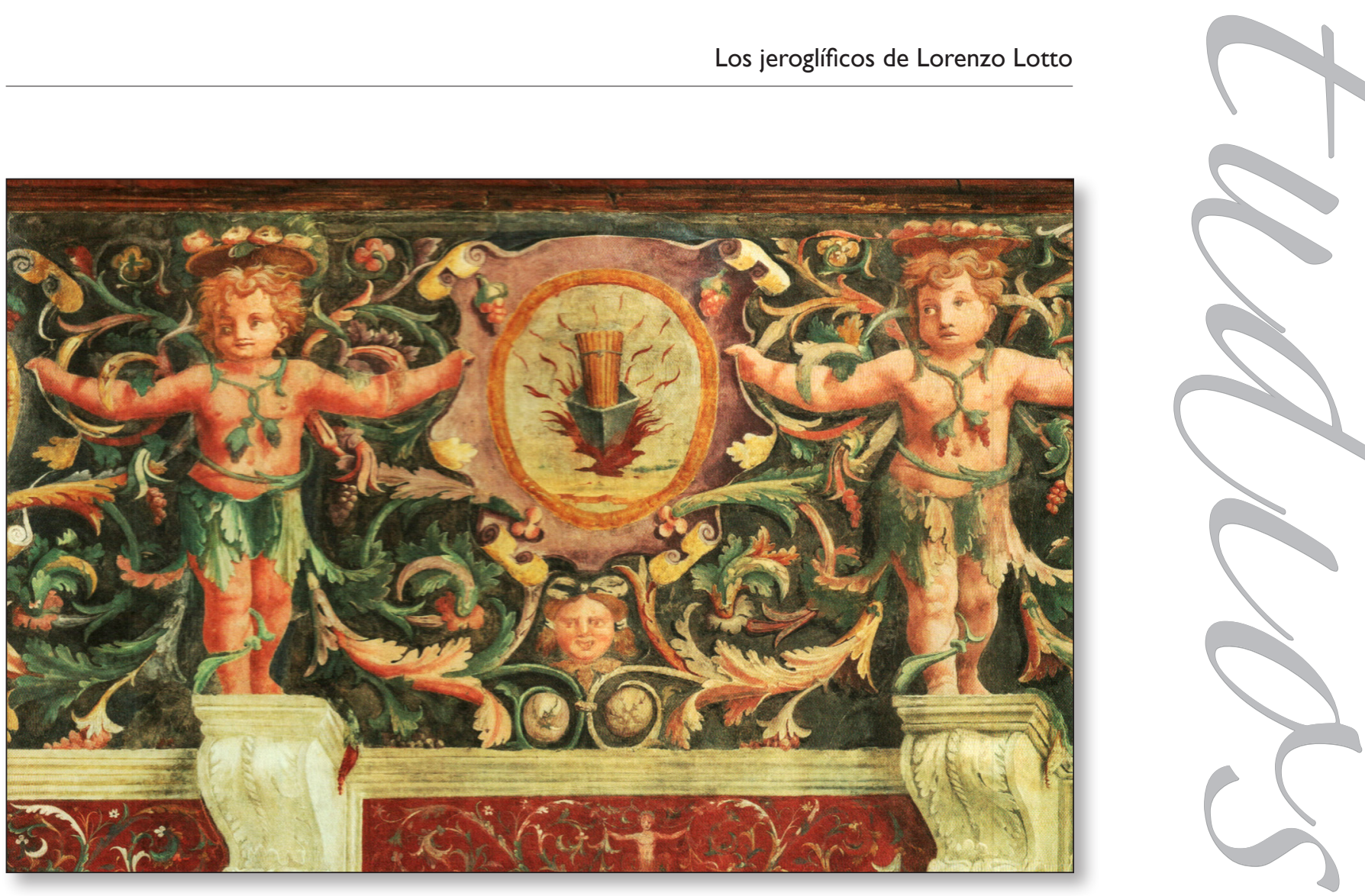

Fig. 8. Empresa de Federico II Gonzaga. Fresco. Sala de las Empresas, pared oeste. Palazzo Te. Mantua.

Al final tenemos que enfocar la atención hacia el objeto puesto al centro del estante, que es un crisol posado sobre un fuego y que contiene siete varas de oro. Hasta la fecha las mayores dudas permanecen sobre el material de las varas, que Cortesi Bosco interpreta de metales variados (Cortesi Bosco, 1987a: 396). Por mi parte me inclino a reconocerlas como oro, de acuerdo con un pasaje de Sabiduría: «Sufrieron [los justos] pequeños castigos, recibirán grandes bienes, porque Dios los puso a prueba y los halló dignos de él. Los probó como oro en el crisol y los aceptó como sacrificio de holocausto" (Sb 3,5-6). Esta identificación es además confirmada por la empresa de Francesco II Gonzaga, donde, junto a esa imagen, está también el mote "Probasti me, Domine, et cognovisti» que ayuda a la interpretación ${ }^{59}$ [fig. 8]. Las varas se reconocen en su materia dorada gracias a la descripción de la empresa que nos deja Paolo Giovio, ${ }^{60}$ mientras que las palabras del mote citan un pasaje del Salmo 139, versículos 1-2. Pues, es plausible que Lotto conociera esta empresa y su sentido, del mismo modo que el adagio erasmiano titulado "Aurum igni probatum». El humanista holandés con este proverbio crea un paralelo entre el oro, probado por el fuego, y la fe, puesta a prueba por las adversidades. Así como el fuego no deteriora el oro, sino que lo hace más brillante,

ver si parte, e scopre./[...]Perché ciò che riluce non è oro,/Né la festa sempr'è dov'è l'alloro:/Ma la prudenza nostra/Sempre pel bianco, ben conosce il nero;/E questa ne dimostra/Qual sia il metallo alchimiato, o'l vero./Quanti si mostran'oggi dotti, o saggi,/Quanti ricchi, e gentili,/Che stolti saran poi, poveri, e vili,/Se noi col paragon ne facciamo saggi?"

59. Después Francesco II, esta empresa fue recuperada por Vincenzo Gonzaga y la usó tanto a título personal como para el Orden de los Redentores; cfr. Burattelli, 1999: 6.

60. Giovio, 1556: 49-50: "Francesco di Gonzaga S. di Mantova [...] usò per impresa come cosa che molto quadrava a suo proposito, un cruciolo al fuoco pieno di verghe d'oro [...]». Véase también Jovio, 2012: 209-210.

IMAGO, NÚM. 9, 2017, 123-149 
de la misma manera el hombre más recto logra superar las más complicadas dificultades sin perder su virtud. ${ }^{61}$

Lorenzo Lotto, en todas sus creaciones simbólicas para el coro, capta la atención de los espectadores subrayando un momento preciso del episodio bíblico, como ocurre también en el arca de Noé. En este caso, el artista se enfoca en la renovación del género humano puesto en obra por medio del diluvio. Al referimos otra vez al comentario ambrosiano, conseguimos entender la elección del artista, que nos muestra estos jeroglíficos con el arca a la merced de las olas, y con la pequeña puerta abierta para acoger a la paloma de regreso con la ramita de olivo. Con relación al relato bíblico, nos damos cuenta que es éste ya el tercer intento efectuado por Noé desde el final del diluvio. En un primer tiempo el patriarca liberó un cuervo para controlar si las aguas se habían retirado, pero el ave se quedó en el exterior, a pesar de que el mundo estuviera todavía sumergido y el animal no tenía donde apoyarse. ${ }^{62}$ Fue entonces el turno de una paloma, que al contrario de su oscuro predecesor, volvió al arca porque el agua recubría todavía las tierras. ${ }^{63}$ En fin, llega el momento narrado. Tras siete días, Noé volvió a enviar a la paloma de exploración y ésta regresó con la ramita de olivo. Según la exégesis ambrosiana, este ramo remite a la sencillez que infunde la enseñanza de la recta virtud. De ese modo se incita a su constante aplicación para vivir conforme a la norma, y además, se provoca en el pecador el deseo de penitencia y de modificar su conducta hasta entonces retorcida. ${ }^{64}$

Otra particularidad de la imagen reside en las tres frondas de olivo que exhiben sus cimas sacudidas por las olas sobre la superficie del agua. Esos árboles aluden a los tres hijos de Noé, Sem, Cam y Jafet, que irán a repoblar la tierra al final del diluvio $(G n 9,18)$. En este sentido, es posible referir a los olivos el significado de paz y de su restablecimiento en la relación entre el hombre, ya purificado, y Dios. Similarmente, pueden indicar también la clemencia de Dios hacia el hombre, o aún la victoria del género humano, todas estas acepciones que se encuentran en una amplia literatura. ${ }^{65}$

Para concluir con esta taracea, es preciso apuntar cómo los tres objetos en el anaquel de la cubierta tienen un doble nivel de significación en relación con los símbolos del arca. Por lo que respecta al primer grado, más inmediato, las herramientas remiten a la práctica alquímica, que es la temática más conocida a nivel popular, donde los metales se purifican hasta alcanzar nueva forma, una nueva regeneración. A nivel más alto, nos presentan el momento preciso del acontecer de la "restauratio humana» del mote. Los objetos son una alegoría visual tanto de las elecciones selectivas efectuadas por Noé, como de las acciones

61. Erasmi Roterodami, 1513: f. 241r, adagio XLIIII: "Aurum igni probatum, dicitur is, cuius fides rebus adversis explorata, spectataque est. Utitur hac similitudine [...] Est autem illud auro non citra miraculum peculiare, est igni non solum non fiat detersi, sed magis ac magis enitescat. Itidem is, qui vere bonus est, obiectis malorum procellis illustrat animi virtutem, non amittit». Vid. así mismo otras fuentes, tanto literarias como emblemáticas sobre este tópico de la prueba del oro en el crisol, propuestas por García Mahíques (1988: 37-39), a propósito de la Empresa I: «Explorare labor» de Núñez de Cepeda.

62. En la exégesis del obispo milanés esta ave alude a los pecados y descaros que, de la misma manera que el cuervo, se alejan de la mente del justo, que de esta forma purifica sus culpas; cfr. Ambrosio, Noe, XVII, 62; PL XIV, 411A.

63. Este intento representa la virtud que disipa la culpa, pero sin encontrar donde apoyarse, o sea, sin encontrar lugar apropiado para su vida, regresa al barco, que representa la mente del justo; cfr. Ibid., XVIII, 64; PL XIV, $411 \mathrm{D}$.

64. Ibid., XIX, 67; PL XIV, 413B.

65. Sobre el olivo como símbolo de paz y victoria véase Valeriano, 1556: LIII, ff. 387r-v, del cual aprendemos que este sentido se debe a Heracles, que ordenó a Etolio, árbitro en las olimpiadas, de coronar el ganador con hojas de acebuche que el mismo Heracles llevó desde la tierra de los hiperbóreos; cfr. Píndaro, Ol., III, 11 s.; Diodoro Sículo, IV, 14; Pausanias, V, 115, 3. Para otras noticias sobre el olivo cfr. Murr, 1890: 40-48; Colonna, 2006: II, 611; Alciato, 2009: 638, n. 5; 647, n. 1; Graves, 2008: 498-499; 501, n. 14. 
de Dios hacia el género humano. La piedra de toque alude entonces a la obra de ensayo que Dios hizo sobre las almas de los hombres. El oro al interior del crisol sobre el fuego se refiere también a la obra de purificación de la corrupción humana y a la ya refinada alma de los justos (Noé) probada por Dios. Al final, la balanza con sus pesas es el símbolo de la justicia de Noé sopesada por Dios (Gn 6,9; Si 4,17), pero también de la ponderación de las almas humanas, ahora regeneradas, que Dios realizó.

\section{JUDIT, LA GLORIA DE LA VIUDEZ}

Los dos paneles, o cubiertas, de taracea examinados anteriormente están separados de los otros dos por el arco de medio punto que permite el acceso al coro de los religiosos, el cual crea una especie de cesura entre las dos partes del programa. La primera historia que encontramos en esta segunda parte es la de Judit, cuyo proyecto fue terminado por Lorenzo Lotto en julio de 1527, y que aparece depositado con las demás taraceas en el inventario del año $1530 .{ }^{66}$ Esta cubierta, de la misma manera que la sucesiva de David y Goliat, está compuesta con criterios diferentes a los recién analizados. De hecho, está claramente relacionada con la historia inferior, de la cual recupera la mayoría de los elementos significantes que, por otro lado, parecen organizados en la superficie de la taracea según las reglas del arte de la memoria clásica. La historia, además, se desarrolla gráficamente a modo de una narración continua [fig. 9]. A la derecha se observan los soldados asirios que, acampados entre los valles cerca de Betulia -ciudad que asediaban y que aparece en el pico de la colina a la izquierda-, yacen dormidos después del banquete que, según la palabra bíblica, el general Holofernes hizo preparar en el cuarto día de asedio, cuando acudió Judit, en compañía de su esclava, bellamente ataviada y adornada con una mitra (o diadema) que ciñe su cabellera. A causa de este banquete, el general quedó ebrio, así como todos sus soldados, que por ello dejaron a Judit a solas con Holofernes, cuya suerte se narra en la parte central de la historia. Esta mujer se aleja a toda prisa de la tienda donde yace el general sin vida, mientras que esgrime la cimitarra ensangrentada en la mano derecha y en la mano izquierda lleva la cabeza de Holofernes, la cual es introducida en la alforja que sujeta su circunspecta sierva. Al final, la sección izquierda nos muestra el rescate de la ciudad de Betulia por parte de los hebreos, que secundaron los dictámenes de Judit y por eso derrotaron al ejército asirio. ${ }^{67}$ Observando la cubierta alegórico-jeroglífica vemos algunos de los elementos recién descritos conectados entre sí por una cinta que dibuja una forma de «M» [fig. 10]. Como bases de esta letra se hallan la cimitarra, a la izquierda, y la cabeza de Holofernes que pende de la cinta, a la derecha. En ambos lados, por encima de estos elementos, encontramos dos palmas anudadas en forma de una "X», mientras que la parte más importante del conjunto alegórico es aquella central, donde el artista aísla el mensaje que los fieles tienen que aprender. Aquí encontramos una corona sobre la parte horizontal de la cinta, de la cual, por medio de un cordel, pende enlazada una anilla, a través de la cual pasa la mitra y, al final, la tableta con el lema "viduitatis gloria».

66. Carta de 15 de julio de 1527 e inventario con fecha de 2 de junio 1530, en Cortesi Bosco, $1987 \mathrm{~b}: 13 ; 21$.

67. Es ésta la única diferencia entre la imagen y la palabra bíblica, que relata que la cabeza de Holofernes fue colgada en la muralla de la ciudad (Jdt 14,1; 14,1 1), mientras que Lotto decidió variar su representación al mostrarla clavada en una pica que es llevada por un soldado hebreo. Eso por claros motivos de composición. 


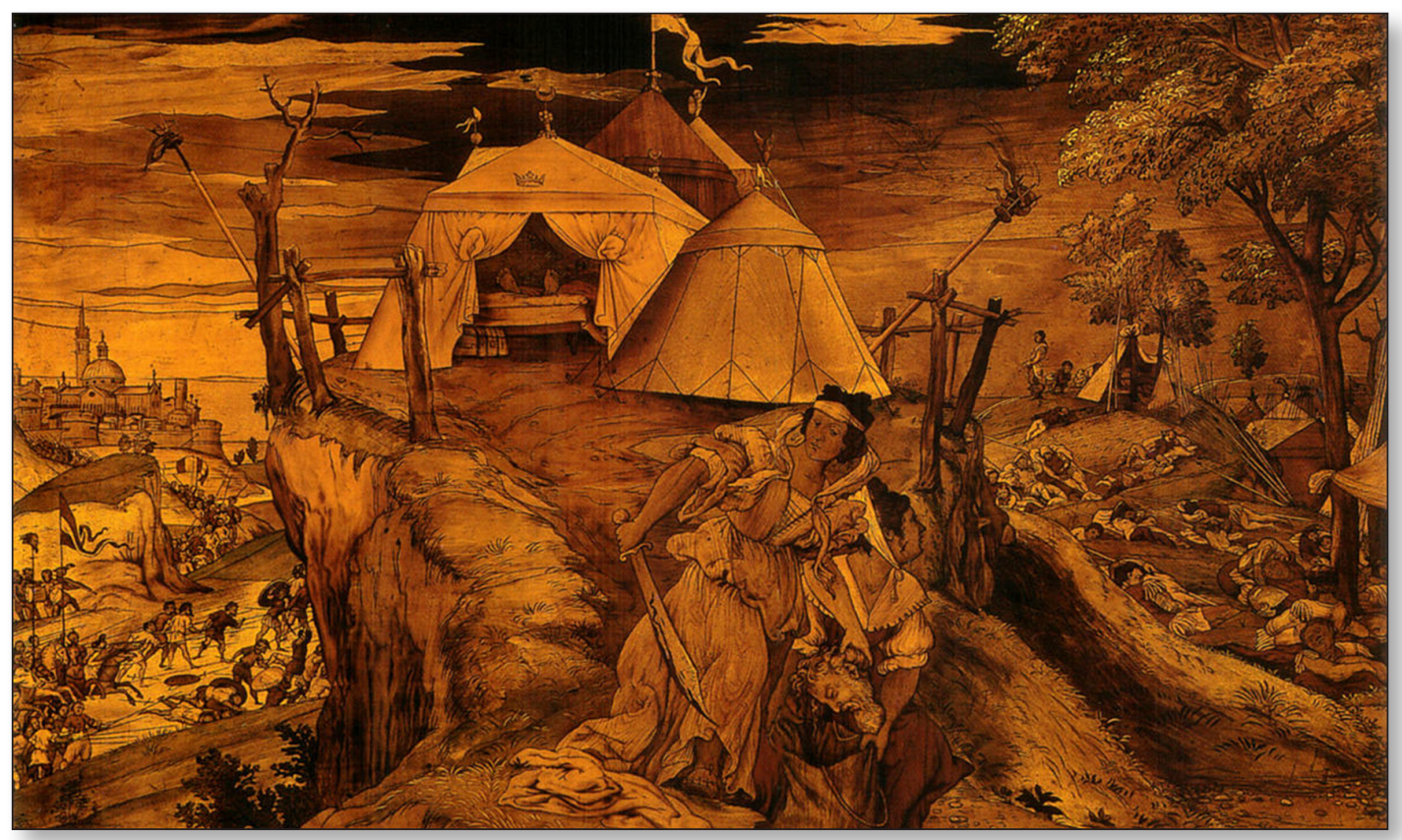

Fig. 9. Lorenzo Lotto (dibujo) y Giovan Francesco Capoferri (taracea). Judit y Holofernes. Historia bíblica (cm. $68 \times 100,30)$. 1527. Santa María la Mayor. Bérgamo.

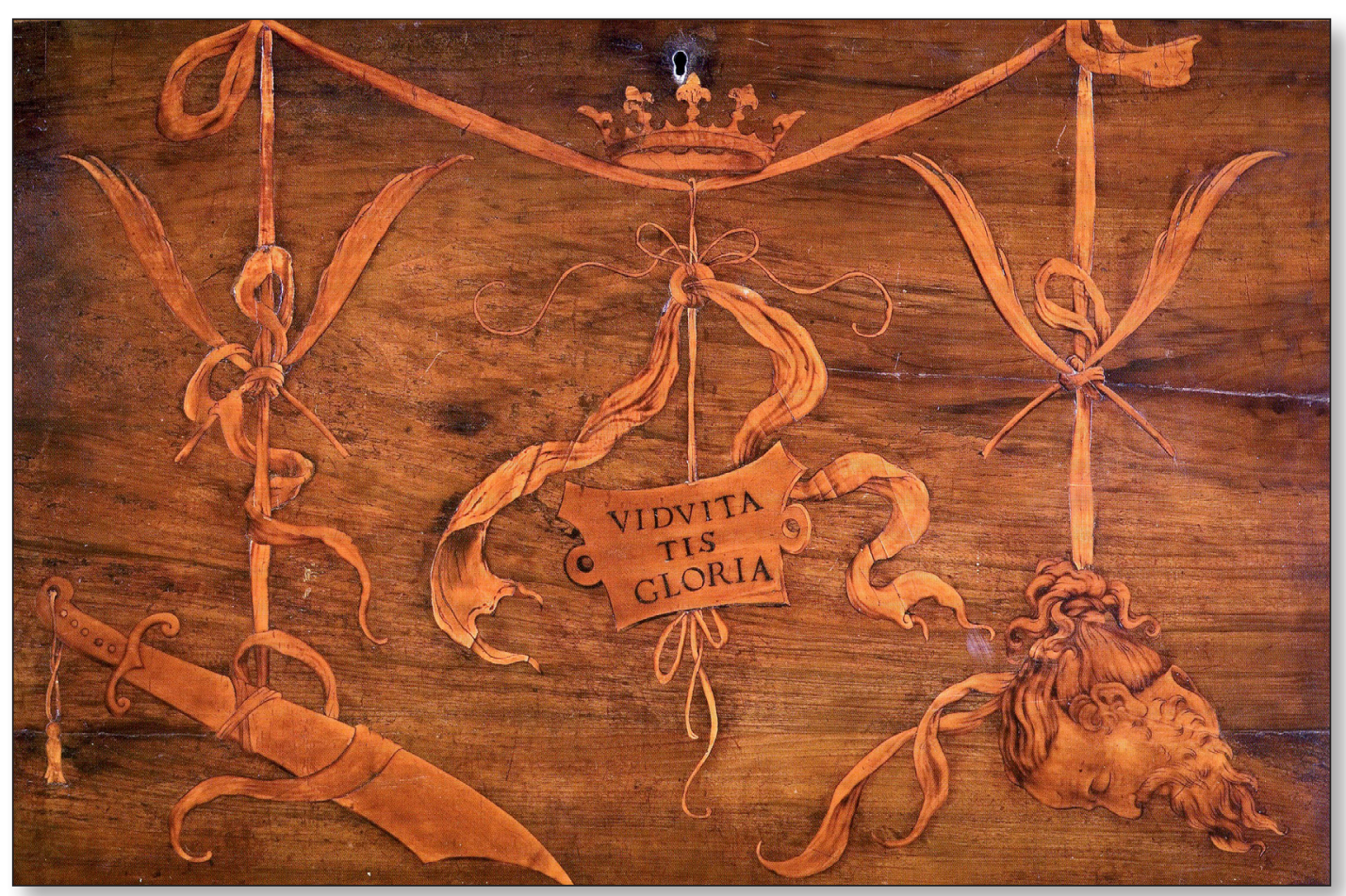

Fig. 10. Lorenzo Lotto (dibujo) y Giovan Francesco Capoferri (taracea). Viduitatis gloria. Cubierta simbólica (cm. 75,20x109,50). 1527. Santa María la Mayor. Bérgamo. 
Nadie había prestado atención a la mitra antes que Cortesi Bosco en 1987 (Cortesi Bosco, 1987a: 475-476), aun cuando ésta es un elemento fundamental en la composición. Se trata de una ornamentación femenina ${ }^{68}$ destinada a embellecer la melena ${ }^{69}$, y fue utilizada sobre todo por las mujeres vírgenes como signo distintivo de la santificación del cuerpo, similar a la corona de la gloria virginal..$^{70}$ Exactamente esta definición remite a la representación tanto de la corona como del mote. Por lo que respecta a la corona, ésta en la historia remata la tienda del general Holofernes e indica la casa del rey Nabucodonosor, mientras que en la cubierta, remata la composición entera y significa la gloria virginal. Eso porque fue una sola mujer hebrea, viuda virtuosa, la que se burló del poder del rey Nabucodonosor llegando a ser orgullo de Israel (Jdt 14,18; 15,9).

El mote «viduitatis gloria» contribuye a explicar la representación de la cubierta y simplifica la recepción del mensaje por parte de los fieles. Entre las posibles interpretaciones, Judit puede ser interpretada como prefiguración de la Virgen, con su viudez asimilada a la virginidad. ${ }^{71}$ Ambrosio explica este concepto citando más veces el pasaje paulino sobre la libertad otorgada por la virginidad y por la viudez, en contraposición a la servidumbre del matrimonio. ${ }^{72}$ Virginidad y viudez eran asumidos como valores personales e interiores, capaces de provocar la libertad de quien sabe dominar los instintos del cuerpo y al mismo tiempo frenar las pasiones y los sentidos materiales (Ambrosio, Exhort. Virg., XXIII; PL XVI, 343A). La Virgen encarna el ideal del "vir sapiens», el de la originaria libertad del hombre antes de que pecara (Ambrosio, Noe, IX, 30; PL XIV, 394B). En particular, el concepto de viudez estaba atado al de virginidad, dado que la indisolubilidad del vínculo matrimonial mandaba que, después de la muerte de uno de los consortes, la atadura no desapareciera, permaneciendo vivo el deber de fidelidad. La viuda guarda su fe hacia el primer marido, pero aun hacia la Iglesia y la palabra de Dios, como ha dispuesto la primera carta a Timoteo (1 Tm 5,3-12). De esa manera se compara la virtud de la viudez con la de virginidad, y Ambrosio trae como ejemplo positivo precisamente a Judit, ${ }^{73}$ que ya menciona en el De Virginibus para su elección de fe, con la cual conservó su pudor y su patria (Ambrosio, virg., II, 24; PL XVI, 213C). Judit se levanta como ejemplo de fortaleza capaz de superar la debilidad del sexo (Ambrosio, vid., VII, 37; PL XVI, 246A), así que, gracias a su virtud, logró salvar a los judíos de la ruina y defenderlos de sus rivales. Ella se quedó casta y mantuvo la pureza entre las hordas asirias, sin caer en tentación y consiguiendo decapitar al enemigo. Gracias a su virtud de viuda derrotó a su índole humana, fortaleciendo su pueblo (Ambrosio, vid., VII, 40-41; PL XVI, 246D-247A). Por eso la viudez es maestra de fe y de castidad, y no tiene que ser vista como un suplicio. Al contrario, tiene que ser abarcada como un premio, tanto más que después de su hazaña, la misma Judit siguió en su fidelidad al fallecido esposo, sin abandonarse a las lisonjas de otros hombres (Jdt 16,22).

En resumen, la cimitarra remite al instrumento de la derrota de Holofernes, que es alegoría del pecado y de la herejía pagana, que en la tercera década del siglo XVI azotaba a toda Europa por medio de la Reforma y de la insidia musulmana. La cabeza arrancada del cuerpo del general indica la derrota del pecado, y las ramas de palma aluden a la victoria

68. Isidoro, Etym., XIX, 31, 1-4.

69. S.v. "Mitra». en Enciclopedia Italiana Treccani, 1934.

70. Isidoro, Eccl. Off., II, 17; PL LXXXIII, 807B: «mitram quasi coronam virginalis gloriae praeferat in vertice».

71. Véase san Buenaventura, referido por Réau (1996: 381, n. 19). Análogamente Nicolás de Lira, referido por Cortesi Bosco (1987a: 473).

72. 1 Co 7,34-40. El pasaje fue utilizado aun por san Agustín (De bono vid., V, 6; PL XL, 434) que entiende el estado viudal incluso superior a la castidad del matrimonio.

73. Lo mismo hace Isidoro, Eccl. Off., II, 18; PL LXXXIII, 807B.

IMAGO, NÚM. 9, 2017, I23-I49 
sobre el mal. ${ }^{74}$ En la zona central, la corona significa la gloria, mientras que la mitra indica la viudez de Judit. Estos últimos dos conceptos quedan resumidos en el mote, que consigue ser extrapolado directamente de los pasajes bíblicos que han convertido la hazaña de esta viuda virtuosa en el honor de la gente de Israel (Jdt 13,15; 15,9).

\section{DAVID, EL TRIUNFO DE LA VIRTUD}

La última composición creada por Lorenzo Lotto para la portada del coro fue aquella relativa al episodio de David y Goliat, la cual ya estaba lista para su envío por parte del artista el 3 de febrero $1527 .{ }^{75}$ Como en el caso precedente, las representaciones de la cubierta aluden a los elementos más explicativos y reconocibles de la historia que protegen, y por eso se observa primeramente la taracea que representa el episodio de David. Al igual que la historia anterior de Judit, estamos frente a una narración continua, con más episodios que se despliegan en la misma superficie lignaria. Esta última es ideada como un bastidor teatral, cuyo fondo principal es la sala del consejo donde Saúl, sentado en un nivel más alto que los demás, recibe a David que se ofrece para luchar contra Goliat. Un siervo que entra por la puerta lateral trae la armadura a David que, según dicen las Sagradas Escrituras, decidió no ponérsela porque era muy pesada. Saúl aparece sin corona y desprovisto de atributos regios, pero está colocado bajo un baldaquino rematado por una media luna puesta sobre un globo, es decir, el símbolo habitual del Islam. Éste último alude al espíritu maligno que cayó sobre Saúl tras haber desobedecido la orden divina de exterminar a los pecadores de Amalec. ${ }^{76}$ De esa manera, el Señor rechazó a Saúl como rey del pueblo israelita y escogió a David, investido por el espíritu genuino. ${ }^{77}$ Después de la hazaña del joven contra Goliat, los celos de Saúl hacia David creció hasta quererlo matar, y en uno de los enfrentamientos entre los dos, el viejo rey de Israel dijo al joven: «Eres mejor que yo, pues tú me tratas bien, mientras que yo te trato mal» (1 S 24,18). La media luna indica entonces la hostilidad de Saúl hacia David, o sea, él no tenía más el favor de Cristo hacia quien lo poseía.

Volviendo a la taracea [fig. 11], en el centro, a la manera de proscenio, observamos a David matando a Goliat, mientras que a sus lados, en el fondo, aparecen dos episodios colaterales descritos al comienzo y al final del relato bíblico. A la izquierda, vemos a David que

\footnotetext{
74. La palma asume los significados de triunfo y renacimiento gracias a sus capacidades; de hecho, cuando es cargada por un peso no se rompe, sino que reacciona volviendo a tomar su forma originaria. Por ese motivo asume significado de victoria, come transmitido por fuentes clásicas como Teofrasto, Hist. Pl., V, 6, 1; Estrabón, XV, 3; Pausanias, VIII, 48, 1-2; Plinio, HN, XVI, 222-223; Apuleyo, Met., II, 4. Sobre la palma en la época clásica véase Murr (1890: 48-50). Erasmo habla largamente sobre este argumento con respecto al adagio "Palmam ferre» (Erasmi Roterodami, 1513: f. 32r, Adagio CCII), explicando que "palma per se victoriam significat». Además, refiere un pasaje de Aulo Gelio (III, 6) que a su vez hace referencia a Plutarco (Quaest. Conv., VIII, 4, 5, 724E-F) y Aristóteles ([Pr.], fr. 229; ed. Rose, Leipzig, 1886, 177). Humanistas como Francesco Colonna, Bartolomeo Platina, Filippo Beroaldo, Leon Battista Alberti y Pierio Valeriano relatan todas estas fuentes; cfr.: Valeriano (1556: L, ff. 369r-370v).

75. Carta con fecha de 3 de febrero 1527, en Cortesi Bosco (1987b: 15-16).

76. 1 S 15. Lotto utilizó un baldaquino semejante también en los frescos de las historias de Santa Bárbara en el oratorio Suardi en Trescore, donde el juez que condena la santa sienta bajo esta arquitectura. Entonces parece que para el artista es algo habitual identificar las herejías con los atributos del Islam.

77. 1 S 16,1-13. David fue ungido rey de Israel por medio del profeta Samuel. Sólo escuchando la melodía de una citara bien tocada Saúl habría logrado sacar de sí mismo este mal espíritu, y por este motivo mandó traer a David, capaz de tocar el instrumento, frente a él.
} 
durante el pastoreo recibe al mensajero de Saúl que lo invita a comparecer frente al rey. Se trata de una reinterpretación del relato bíblico, que refiere, en cambio, que fue el padre Iesse a traer el mensaje de Saúl y a montar al hijo en el asno para conducirlo hacia la corte del rey. Exactamente por encima de esta escena vemos otra que representa a David mientras protege su rebaño del ataque de un oso y de un león, algo que el mismo David relata a Saúl, cuando se propuso como retador de Goliat. ${ }^{78}$ En la parte derecha, en primer plano, el desconcertado pueblo y los combatientes de Israel miran a David que, dejando abandonada en el suelo la armadura, arroja con su honda la piedra que antes había recogido. El gigante Goliat golpeado en medio de la frente se desequilibra y, más a la izquierda, el pequeño David se lanza sobre el herido Goliat intentando conseguir su cabeza como trofeo. La secuencia de la historia llega a su conclusión en el fondo a la derecha, donde David se dirige hacia Jerusalén sujetando la espada y la cabeza del enemigo. Al llegar le salen al encuentro las mujeres jubilosas sacudiendo ramas y coronas de olivo, además de las palmas de la victoria. También en este caso hay diferencias con el relato bíblico, según el cual las mujeres fueron al encuentro del rey Saúl, entonando cantos tanto en honor de éste como de David, al cual dedicaron las honras mayores. Lotto muestra sólo al joven para hacer hincapié en sus valores y en su victoria, aislando sus acciones dentro del relato de las Sagradas Escrituras.

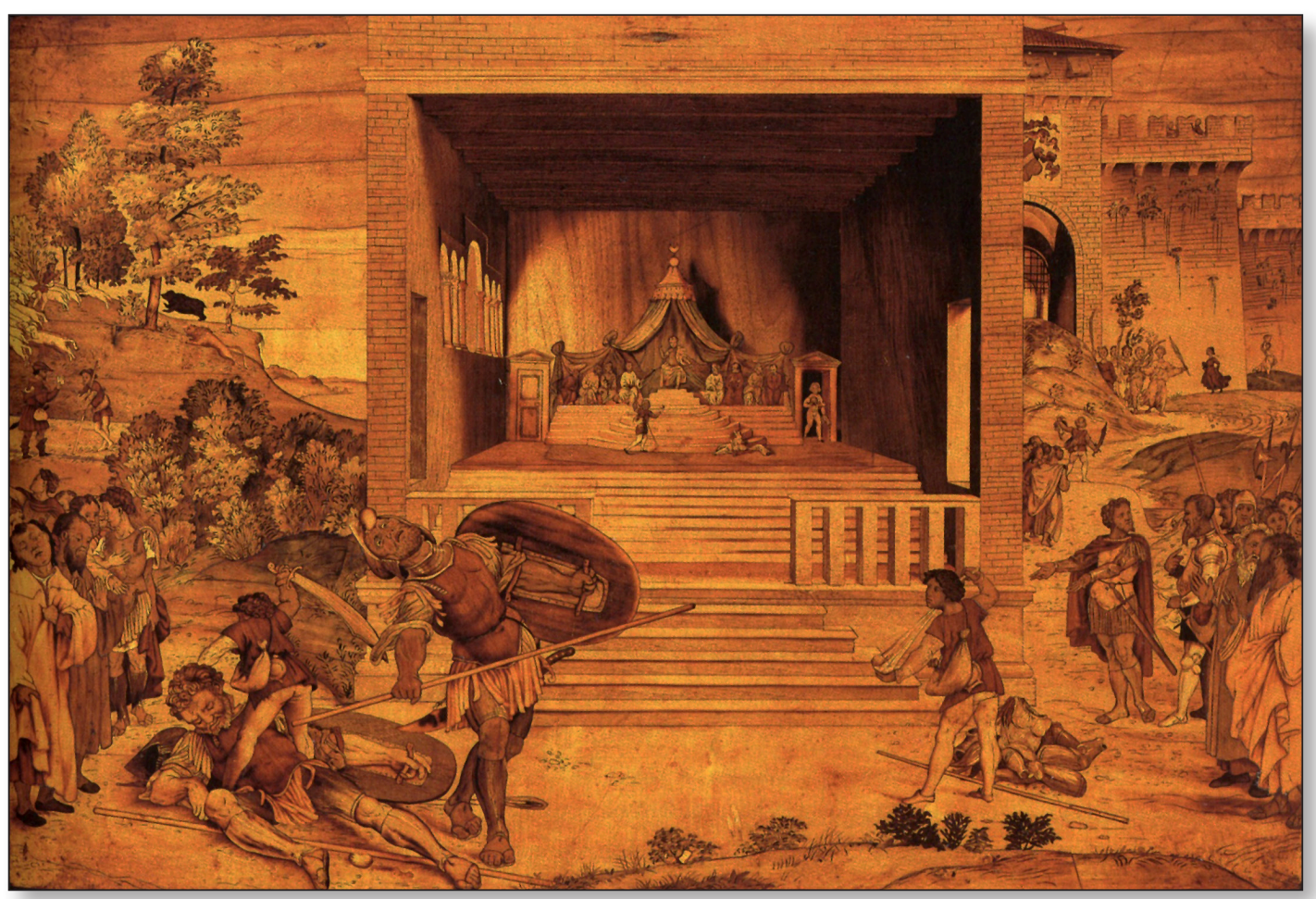

Fig. 11. Lorenzo Lotto (dibujo) y Giovan Francesco Capoferri (taracea). David y Goliat. Historia bíblica (cm. 68x101). 1527. Santa María la Mayor. Bérgamo.

78. El joven contó que una de estas fieras quería llevarse un cordero del rebaño, y él la siguió quitándole la presa de la boca, hasta matarla si fuera necesario.

IMAGO, NÚM. 9, 2017, I23-149 


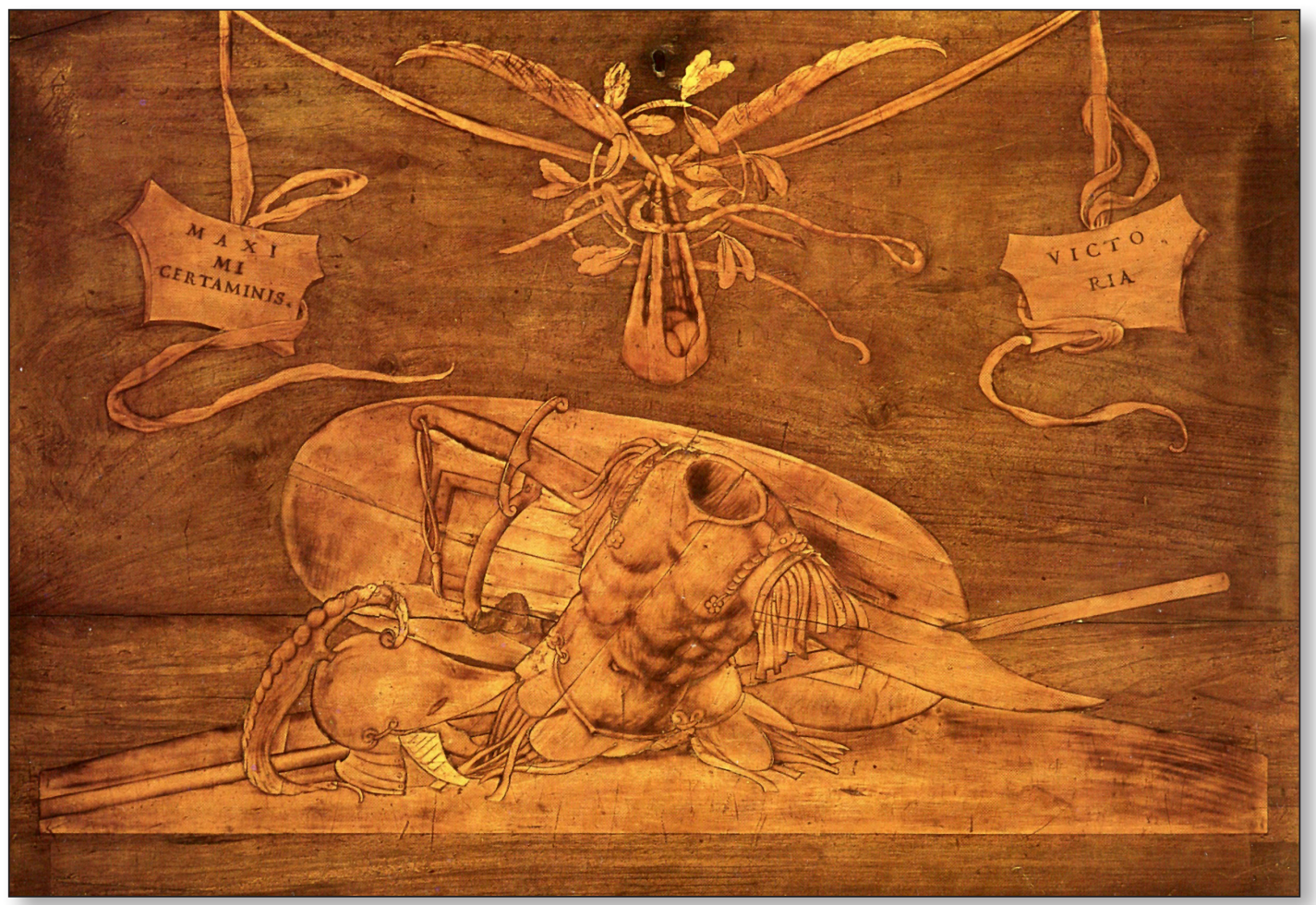

Fig. 12. Lorenzo Lotto (dibujo) y Giovan Francesco Capoferri (taracea). Maximi certaminis victoria. Cubierta simbólica (cm. 76,50x109,50). 1527. Santa María la Mayor. Bérgamo.

Los atributos del jeroglífico presentado en la cubierta recuperan solamente los elementos que mejor evocan la historia [fig. 12]. En medio, en la parte inferior, dispuestos a modo de trofeo: una loriga, una espada, un escudo, el asta de una lanza y un yelmo, que remiten a la armadura de Goliat, que aquí tiene que ser interpretada también como las panoplias que se podían ver durante los triunfos clásicos, donde se llevaban en procesión semejantes armaduras. Exactamente al triunfo de David remite también la parte superior de la cubierta, donde los elementos están conectados entre sí por una cinta que visualmente forma una "M», como en la tableta precedente. En los dos extremos se encuentran las dos inscripciones que forman el mote, mientras que al centro el artista ideó una composición formada por piedras puestas dentro de una honda, a su vez rematada por una corona de olivo y por dos palmas cruzadas que la atraviesan en el medio. La honda con las piedras corresponde al instrumento utilizado por el pequeño David para derrotar a Goliat, mientras que la corona con las palmas cruzadas alude a la victoria que el joven virtuoso obtuvo por medio de ese instrumento. ${ }^{79}$

79. Sobre la palma como símbolo de victoria remito a la nota 75. Por lo que respecta al olivo, este es el habitual atributo de Atenea, como aprendemos de Homero, Od., XIII, 372; Apolodoro, Bibl., III, 14; Ovidio, Ars., II, 518; Met., VI, 81-82; XIII, 653; Marcial, I, 76; Virgilio, G., I, 18-19; Cornuto, Theol. Graec., 38-39, y de este último aprendemos que el árbol puede denotar la pureza y la virginidad. En efecto, el aceite no es fácilmente adulterable a través de otro líquido, sino siempre se queda puro, no mezclado, hasta aparecer conforme a la virginidad. El olivo identifica también la sabiduría y la inmortalidad de la diosa, pero entre sus significados hay también la de paz y victoria, que aquí más nos interesa y por los cuales remito arriba a la nota 66. 
Se trata entonces de elementos que encontramos en la historia veterotestamentaria empuñados por las mujeres que salen de la muralla de Jerusalén en alabanza de David. ${ }^{80}$

El mote se compone de dos inscripciones. La primera tableta reza "maximi certaminis», mientras la siguiente lleva la palabra "victoria». "La victoria más grande dentro del conflicto" es aquella obtenida por David, joven pastor tocador de cítara que, ungido por el Señor, halló la fuerza y el coraje de retar al extranjero Goliat. Esta fuerza fue transmitida por medio de la fe, gracias a la cual la firmeza de uno solo llegó a ser la victoria de todo el pueblo hebreo (Ambrosio, Apol. Dav., VI, 26; PL XIV, 902C). De este modo, interpreta el episodio Ambrosio de Milán, y además en las Sagradas Escrituras se describe a David como hijo de Jesé "fuerte, valiente y hombre de guerra, juicioso en el hablar y de buena presencia» (1 S $16,18)$, tanto que el Señor lo escogió por su cualidad de virtuoso, porque Dios no mira el aspecto, sino al corazón (1 S 16,7).

La invención del artista italiano para esta cubierta es una alabanza a la figura de David y sobre todo de la virtud que lo condujo a la gracia del Señor, que hizo descender su espíritu sobre él para ayudarlo a vencer al campeón de los gentiles. Es precisamente ésta la suerte que corresponde a los fieles que respetan el recto camino en sus vidas, o sea, que abarcan la verdadera fe cristiana que los llevará a renegar de los pecados, del mismo modo que David derrotó a Goliat. Es posible configurar la cubierta exactamente como un verdadero triunfo, práctica muy en boga durante el Renacimiento, como ya se ha expuesto en el caso del hundimiento del faraón. En las representaciones renacentistas de los triunfos solemos encontrar los mismos elementos que Lotto nos ofrece, es decir, panoplias, armas, palmas y olivos. ${ }^{81} \mathrm{El}$ triunfo de David, de su virtud y, más generalmente, la del hombre liberado de sus pecados y capaz de seguir la palabra divina.

\section{EL DISCURSO VISUAL DEL CONJUNTO}

Para entender lo mejor posible el mensaje del conjunto de los episodios veterotestamentarios significados, tenemos preliminarmente que volver al concepto del diluvio. Este episodio, de acuerdo con Ambrosio, remite a la purificación y a la siguiente resurrección. Según un grado de significación literario, el Señor retuvo el uso del cuerpo y el podrido modo de vida de la generación humana exactamente por medio de la purificación del diluvio. A un nivel de interpretación más profundo, en la imagen del diluvio podemos ver la depuración del alma. En este sentido, cuando nuestra mente se purifica de las lisonjas corporales del mundo, gracias a los buenos pensamientos recién adquiridos, ésta consigue volver a lim-

80. El símbolo de las dos palmas cruzadas fue utilizado por Lotto también en un retrato del 1543, probablemente de Marcello Framberti, donde aparecen símbolos jeroglíficos colgados a un festón de laurel. Para una hipótesis sobre estos símbolos véase Dezuanni (2005: 51-56).

81. Encontramos representaciones artísticas del triunfo de David, por ejemplo, sobre cajones, como aquél realizado por Pesellino hoy en día en la colección de Christopher Loyd en Locking House, en el Berkshire, o aquello del taller de Apollonio di Giovanni, conservado en el Museo Horne de Florencia. Los dos hacen juego con otro panel con la representación de la lucha entre David y Goliat. Según esta lógica parece que Lotto desarrolla una operación semejante, representando en la tableta veterotestamentaria el relato de David que culmina con la lucha contra Goliat. Esa puede hacer juego con la cubierta que presenta el triunfo. Además, los triunfos de David eran preparados realmente como espectáculo-cortejo durante la fiesta de San Juan en Florencia. No es entonces una novedad aquella de enseñar la victoria de David celebrándolo por medio de elementos de un verdadero triunfo; cfr. Carandente (1963: 66; 79; 131, n. 153; 133; 173).

IMAGO, NÚM. 9, 2017, I23-149 
piarnos del lodo de nuestra pasada concupiscencia. ${ }^{82}$ Esta doble purificación, corporal y espiritual, alude a la muerte del hombre por medio de las aguas del diluvio y a la purificación de la humanidad que, gracias a la «limpieza» realizada por estas aguas, podrá volver a empezar con una nueva "virginidad» de pecados y vicios. Con esta segunda acepción comprendemos la referencia al sacramento del bautismo, y de esa manera se inserta plenamente en la significación general de las cuatro cubiertas del iconostasio. Se trata de un recorrido que conduce desde la reiterada pecaminosidad del faraón, que con su estolidez no logró reconocer la verdadera divinidad, hasta la más alta virtud, la de David. Según esta perspectiva, Lotto, con sus símbolos, hace referencia exactamente al bautismo; al principio evidenciando el pecado del faraón que es ahogado en las aguas del mar Rojo/bautismo por las cuales fue sumergido. Justo después, con los jeroglíficos del arca, nos muestra el preciso momento de la emersión de las mismas aguas del diluvio/bautismo, y entonces el renacimiento de la humanidad/individuo que, desde este momento, será capaz de perseguir una vida virtuosa. Ejemplo de esta nueva existencia sin mancha son la gloriosa Judit, cuya viudez es posible compararla con una virginidad de pecados y vicios, y el invicto David, elegido directamente por el Señor. Los dos fueron capaces de derrotar al enemigo/pecado-vicio y salvar sus gentes, y por eso Lotto nos los enseña en las dos taraceas que siguen, o sea, las que van a concluir el programa iconográfico del frente del coro que, empezando con el triunfo de la estolidez del faraón, termina con el verdadero triunfo de David.

\section{BIBLIOGRAFÍA}

Alegris, F. de [1508]. Tractato nobilissimo della Prudentia et Iustitia Laqual debbe havere chadauno Iusto signore [...], Venetia, Melchior Sessa.

Alciato, A. [2009]. Il Libro degli Emblemi secondo le edizioni del 1531 e del 1534, introduzione, traduzione e commento di M. Gabriele, Milano, Adelphi.

Allen, d. C. [1970]. Mysteriously Meant: the Rediscovery of Pagan Symbolism and Allegorical Interpretation in the Renaissance, Baltimore, John Hopkins Press.

Ambrosio de Milán [2013]. El Paraíso. Caín y Abel. Noé, introducción, traducción y notas de A. López Kindler, Madrid, Ciudad Nueva.

Biblia vulgare, novamente impressa, corretta $\theta$ historiata [1525]. Vinegia, Helisabetta de Rusconi. Brant, S. [1494]. Das Narrenschiff, Basel, Johann Bergmann von Olpe.

Brant, S. [2011]. La nave de los necios, Regales Serna (eds.), con 115 grabados atribuidos a Alberto Durero, el maestro de Haintz-Nar, el maestro de Gnad-Her y otros maestros del Renacimiento, Madrid, Akal.

Burattelli, C. [1999]. Spettacoli di corte a Mantova tra Cinque e Seicento, Firenze, Le lettere.

BurcKhardT, J. [2004]. La cultura del Renacimiento en Italia, prólogo de F. Bouza, traducido por T. Blanco, F. Bouza y J. Barja, Madrid, Akal.

Carandente, G. [1963]. I trionfi nel primo Rinascimento, Roma, Edizioni Rai Radiotelevisione Italiana.

Castelli, P. [1979]. I geroglifici e il mito dell'Egitto nel Rinascimento, Firenze, Edam.

Cocchiara, G. [1956]. Il paese di cuccagna e altri studi di folklore, Torino, Einaudi.

- [1963]. Il mondo alla rovescia, Torino, Einaudi.

82. Ambrosio, Noe, XIII, 46; PL XIV, 402B; cfr. Ambrosio de Milán (2013: 301 ). 
Colonna, F. [2006]. Hypnerotomachia Poliphili, a cura di M. Ariani e M. Gabriele. 2 vols., Milano, Adelphi.

Cortesi Bosco, F. [1980]. Gli affreschi dell'Oratorio Suardi. Lorenzo Lotto nella crisi della Riforma, Bergamo, Bolis.

- [1987a]. Il coro intarsiato di Lotto e Capoferri per Santa Maria Maggiore in Bergamo, Cinisello Balsamo, Pizzi.

- [1987b]. Il coro intarsiato di Lotto e Capoferri per Santa Maria Maggiore in Bergamo. Lettere e documenti, Cinisello Balsamo, Pizzi.

Courcelle, P. [2001]. Conosci te stesso: da Socrate e san Bernardo, presentazione di G. Reale, traduzione di F. Filippi, Milano, Vita e pensiero.

DAMIANAKI, C. [2007]. «Il mondo alla riversa. Iconografia e motivi antisociali in alcune stampe popolari italiane del secolo XVI», en: A. Corsaro, H. Hendrix, P. Procaccioli, (a cura di), Autorità, Modelli e Antimodelli nella Cultura Artistica e Letteraria tra Riforma e Controriforma. Atti del seminario internazionale di studi (Urbino-Sassocorvaro, 9-11 novembre 2006), Roma, Manziana, 423-430.

Dezuanni, E. [2005]. Lorenzo Lotto da Venezia a Treviso. Ritratti e committenti 1542-1545, Dosson di Casier, Matteo.

Dieckmann, L. [1957]. "Renaissance Hieroglyphics», Comparative Literature, 4, 308-321.

Diógenes Laercio [1887]. Vidas, opiniones y sentencias de los filósofos más ilustres, traducido directamente del griego por J. Ortiz y Sanz, Madrid, Luis Navarro editor.

Erasmi Roterodami [1513]. Adagiorum Chiliades tres, Basilea, Ioannis Frobenii.

Erasmo da Rotterdam [2013]. Modi di dire. Adagiorum Collectanea. A cura di C. Carena, Torino, Einaudi.

Galis-Wronski, D. [1977]. Lorenzo Lotto: A Study of his Career and Character, with Particular Emphasis on his Emblematic and Hieroglyphic Works, tesis doctoral, Bryn Mayr College, 1977 (facsímil University Microfilms International, Ann Arbor, 1980).

García Mahíques, R. [1988]. Empresas Sacras de Núñez de Cepeda, Madrid, Ediciones Tuero.

GieHlow, K. [1915]. «Die Hieroglyphenkunde des Humanismus in der Allegorie der Renaissance, besonders der Ehrenpforte Kaisers Maximilian I: ein versuch», Jahrbuch der Kunsthistorischen Sammlungen des Allerhöchsten Kaiserhauses, 32, 1-232.

GIFFORD, D. J. [1974]. "Iconographical Notes Towards a Definition of the Medieval Fool», Journal of the Warburg and Courtauld Institutes, 37, 336-342.

Giovio, P. [1556]. Ragionamento di Mons. Paolo Giovio sopra i motti, $\theta$ disegni d'arme, $\theta$ d'amore, che communemente chiamano Imprese [...], Venetia, Giordano Ziletti.

Graves, R. [2008]. I miti greci, traduzione di E. Morpurgo; presentazione di U. Albini, Milano, Longanesi.

GrazZINI, A. F. [1750]. Tutti i Trionfi, carri, mascherate o canti carnascialeschi andati per Firenze dal tempo del Magnifico Lorenzo de'Medici, Cosmopoli, [s.n.].

HARMs, W. [1999]. Wahrnehmungsgeschichte und Wissendiskurs im illustrierten Flugblatt der Frühen Neuzeit (1450-1700), tagung in Ascona, Monte Verità, vom 31. Oktober bis 4. November 1999, Basel, Schwabe.

Horapolo [201 1]. Hieroglyphica, edición J. M. González de Zárate, traducción del texto griego M. J. García Soler, Madrid, Akal.

Hori Apollinis [1940]. Hieroglyphica, saggio introduttivo, edizione critica del testo e commento di F. Sbordone, Napoli, Loffredo.

Iversen, E. [1993]. The Myth of Egypt and its Hieroglyphs in European Tradition, Princeton, Princeton University Press. 
Jovio, P. [2012]. Diálogo de las empresas militares y amorosas, traducción de A. de Ulloa, edición crítica, introducción y notas de J. Gómez, Madrid, Ediciones Polifemo.

Katzenellenbogen, A. [1989]. Allegories of the Virtues and Vices in Medieval art: from early Christian times to the thirteenth century, Toronto, University of Toronto Press.

LEAL, P. G. M. C. [2014]. The Invention of Hieroglyphs: a Theory for the transmission of Hieroglyphs in Early-Modern Europe. PhD thesis (Degree of PhD in Text and Image Studies). 2 vols., University of Glasgow.

Martindale, A. [1980]. Andrea Mantegna: i trionfi di Cesare nella collezione della Regina d'Inghilterra ad Hampton Court, prefazione di A. Blunt, Milano, Rusconi immagini.

Mellikof, R. [1973]. "Riding Backwards: Theme of Humiliation and Symbol of Evil», Viator, 4, 153-176.

Mitchell, B. [1979]. Italian Civic Pageantry in the High Renaissance: A Descriptive Bibliography of Triumphal Entries and Selected Other Festivals for State Occasions, Firenze, Olschki.

Morini, L. (a cura di) [1996]. Bestiari Medievali, Torino, Einaudi.

Murr, J. [1890]. Die Pflanzenwelt in der griechischen Mythologie, Innsbruck, Verlag der Wagner'sche Universitäts.

O'ReILly, J. [1988]. Studies in the Iconography of the Virtues and Vices in the Middle Ages, New York, Garland.

Omodeo, A. [1965]. Mostra di Stampe Popolari Venete del '500, catalogo a cura di A. Omodeo, Firenze, Olschki.

Orapollo [2009]. I Geroglifici, introduzione, traduzione e note di M. A. Rigoni e E. Zanco, Milano, BUR.

Paolino Minorita (fra). [1868]. Trattato De regimine rectoris, Vienna, Tendler \& C.-Firenze, Vieusseux.

Pfeiffenberger, S. [1986]. The Iconology of Giotto's Virtues and Vices at Padua, Ann Arbor, UMI.

PisANI, G. [2004]. "L'ispirazione filosófico-teologica della sequenza "Vizi-Virtù" nella cappella degli Scrovegni di Giotto», Bollettino del Museo Civico di Padova, 93, 61-97.

RéAu, L. [1996]. Iconografía del Arte Cristiano. Iconografía de la Biblia - Antiguo Testamento, Tomo 1/Vol. 1, Barcelona, Ediciones del Serbal.

Saintyves, P. [1935]. "Le charivari de l'adultère et les courses à corps nus», Société d'ethnographie de Paris, 31, 7-36.

SAVARESE, G. y GAREFFI, A. [1980]. La letteratura delle immagini nel Cinquecento, Roma, Bulzoni.

Schiavon, A. [2013]. Le Imprese Geroglifiche di Lorenzo Lotto per l'Iconostasi del Coro di Santa Maria Maggiore in Bergamo, Trabajo Fin de Máster para optar al Título de Master Oficial en Historia del Arte y Conservación de Bienes Culturales, Università degli Studi di Udine.

Sebastián, S. [1986]. El Fisiólogo atribuido a San Epifanio, traducción directa del latín de F. Tejada Vizuete, seguido de El bestiario toscano, traducción del catalán de A. Serrano i Donet, J. Sanchís i Carbonell, Madrid, Edición Tuero.

SORRENTO, L. [1942]. Stampe popolari e libri figurati del Rinascimento lombardo, Milano, Edizioni de "L'Arte".

Tristan, F. [1980]. Le monde à l'envers, étude de F. Tristan et anthologie. La représentation du mythe, essai d'iconographie par M. Lever, Paris, Hachette-Massin.

VALERIANO, P. [1556]. Hieroglyphica, sive de sacris Aegyptiorum aliarumque Gentium litteris comentariorum [...], Basileæ, Michael Isengrin.

VAn Den Berg-NoË, H.A. [1974]. «Lorenzo Lotto e la decorazione del coro ligneo di S. Maria Maggiore in Bergamo", Mededelingen van het Nederlands Historisch Instituut te Rome, 36, 145-164. 
VASARI, G. [2004]. Las vidas de los más excelentes arquitectos, pintores y escultores italianos desde Cimabue a nuestros tiempos, edición de L. Bellosi y A. Rossi, presentación de G. Previtali, Madrid, Cátedra.

Volkmann, L. [1923]. Bilderschriften der Renaissance: Hieroglyphik und Emblematik in ihren Beziehungen und Fortwirkungen, Leipzig, Hiersemann.

Weisbach, W. [1919]. Trionfi, Berlin, Grote.

WiLHeLm, R. [1996]. Italienische flugschriften des Cinquecento (1500-1550): Gattungsgeschichte und Sprachgeschichte, Tübingen, Niemeyer.

WitTKOWER, R. [2006]. La alegoría y la migración de los símbolos, Madrid, Siruela.

ZANCHI, M. [1997]. Lorenzo Lotto e l'immaginario alchemico, Clusone-Bergamo, Ferrari.

- [2006]. La Bibbia secondo Lorenzo Lotto: il coro ligneo della Basilica di Bergamo intarsiato da Capoferri, Clusone, Ferrari.

— [2011]. Lotto: i simboli, Firenze-Milano, Giunti.

Zemon Davis, N. [1980]. Le culture del popolo: sapere, rituali e resistenze nella Francia del Cinquecento, traduzione di S. Lombardini, Torino, Einaudi. 
